\title{
Climatic Drivers of Growth in Mixed Conifer Forests of the Sierra Nevada for Different Tree Sizes and Thinning Treatments
}

Andrew M. Hirsch

amh0044@mix.wvu.edu

Follow this and additional works at: https://researchrepository.wvu.edu/etd

Part of the Forest Biology Commons, and the Forest Management Commons

\section{Recommended Citation}

Hirsch, Andrew M., "Climatic Drivers of Growth in Mixed Conifer Forests of the Sierra Nevada for Different Tree Sizes and Thinning Treatments" (2021). Graduate Theses, Dissertations, and Problem Reports. 8036. https://researchrepository.wvu.edu/etd/8036

This Thesis is protected by copyright and/or related rights. It has been brought to you by the The Research Repository @ WVU with permission from the rights-holder(s). You are free to use this Thesis in any way that is permitted by the copyright and related rights legislation that applies to your use. For other uses you must obtain permission from the rights-holder(s) directly, unless additional rights are indicated by a Creative Commons license in the record and/ or on the work itself. This Thesis has been accepted for inclusion in WVU Graduate Theses, Dissertations, and Problem Reports collection by an authorized administrator of The Research Repository @ WVU. For more information, please contact researchrepository@mail.wvu.edu. 
Climatic Drivers of Growth in Mixed Conifer Forests of the Sierra Nevada for Different Tree Sizes and Thinning Treatments

Andrew M. Hirsch

Follow this and additional works at: https://researchrepository.wvu.edu/etd

Part of the Forest Biology Commons, and the Forest Management Commons 


\title{
Climatic drivers of growth in mixed conifer forests of the Sierra Nevada for different tree sizes and thinning treatments
}

\author{
Andrew M. Hirsch \\ Thesis submitted \\ to the Davis College of Agriculture, Natural Resources, and Design \\ at West Virginia University \\ in partial fulfillment of the requirements for the degree of \\ Master of Science in Forestry
}

Sophan Chhin, Ph.D., Chair

Jianwei Zhang, Ph.D.

Jamie Schuler, Ph.D.

Division of Forestry and Natural Resources

Morgantown, West Virginia

2021

Keywords: mixed conifer, Sierra Nevada, dendrochronology, dendrometer, radial release Copyright 2021: Andrew Hirsch 


\section{ABSTRACT \\ Climatic drivers of growth in mixed conifer forests of the Sierra Nevada for different tree sizes and thinning treatments}

\section{Andrew Hirsch}

The Mediterranean region of northern California is projected to get increasingly warmer under all Intergovernmental Panel on Climate Change (IPCC) emission scenarios, with future precipitation projections not showing much of a trend. This poses a problem to the already dry summers that are experienced in the Mediterranean region of California. If precipitation does not increase alongside temperatures, the dry seasons will likely only get drier. The use of dendroclimatology to assess how mixed conifer species in the Sierra Nevada responded to past climate is a key resource that can be used to infer how trees may respond to a future changing climate. In this study, I assessed and compared responses of small, medium, and large diameter mixed conifer species to different climate variables (temperature, precipitation, and climate moisture index (CMI)). One of the most coherent responses from all diameter groups and across all species was the positive response to increasing minimum winter temperatures. All diameter groups and species also responded positively to precipitation and CMI at some point in the analysis period. Perhaps the most notable difference when comparing the three diameter groups to climate was the higher occurrence of negative responses to temperature of the previous year from the largest diameter group-as well as the higher number of negative responses to temperature in general. These results suggest that larger trees may be more sensitive to future climate projections compared to smaller trees, and they may carry those effects into the next year.

Due to the multiple ecosystem benefits that these iconic large, old growth trees provide, forest managers are applying radial thinning treatments around these legacy trees to improve their vigor and reduce mortality. However, there is limited information on the effectiveness of these treatments. One objective of this current study was to analyze sub-hourly stem fluctuations of legacy ponderosa and sugar pines in multiple different radius thinning treatments to assess the short-term effects of these treatments. Thinning treatments applied were: R30C0 (9.1 m radius), $\mathrm{R} 30 \mathrm{C} 2$ (9.1 m radius leaving 2 competitors), and RD1.2 (radius equaling DBH multiplied by $1 \mathrm{ft} / \mathrm{in}$ multiplied by 1.25). The other objective of this study was to assess climatic drivers of hourly stem fluctuations. Using the dendrometeR package in the program $R, I$ gathered daily statistics (i.e. daily amplitude) of the stem fluctuations, as well as stem cycle statistics such as duration and magnitude of contraction, expansion, and stem radial increment. I then performed correlation analyses between those statistics and the environmental variables to assess the climatic drivers of stem fluctuations as well as try to determine which radial thinning treatment was most effective at increasing growth and vigor. The findings from this study highlighted the important role that mean solar radiation, air temperature, and relative humidity play in stem variations of sugar and ponderosa pine. One of the main findings from a management perspective was that RD1.2 was the only treatment group for sugar pine that contracted less on warmer, higher solar radiation days and put on more stem radial increment on higher solar radiation days. For ponderosa pine, treatment RD1.2 also contracted less on warmer, higher solar radiation days. These findings suggest that the extended radius RD1.2 treatment may be the most effective at releasing legacy sugar and ponderosa pine trees compared to the other treatments applied. 


\section{Acknowledgements}

I would first like to thank my advisor, Dr. Steve Chhin, for your guidance throughout this process. Your expertise and input has improved my work immensely. It was a pleasure working for you these past two years as you always provided positive feedback and helped to further my understanding of any topic that arose during this research. Thank you to the Forest Service for providing funding and making this research possible (Joint Venture Agreement \# 14-JV11272139-016). Thank you, Dr. Jianwei Zhang, for providing data and assistance with tracking down additional resources that made analysis more thorough. Thank you, Dr. Jamie Schuler, for teaching me crucial silvicultural knowledge throughout the years. This knowledge has helped me provide a more thoughtful analysis for this research and will be essential for my forestry career.

Thank you, Eric Yetter, for your help throughout my dendrochronological analysis. You were always willing to provide feedback and assistance while working together in the lab, and it did not go unnoticed. I would also like to thank John Holden for your help with collecting data for the Chhin Lab. Thank you to Dr. Michael Premer, Christal Johnson, Iris Allen, and all the field assistants for collecting the field samples and data that was used for this research. I would also like to thank all of the forestry professors at West Virginia University for helping build my knowledge throughout my time here. Lastly, I would like to thank my partner, Joellen Stivala, and all of my family and friends for their support and advice throughout the years. Without everyone mentioned here, this research would not have been possible. 


\section{Table of Contents}

ABSTRACT

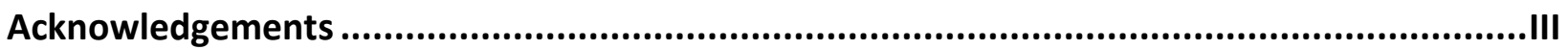

List of Tables ...................................................................................................................................

List of Figures

Chapter 1: Forest Conditions and Current Management Approaches in Northern Sierra

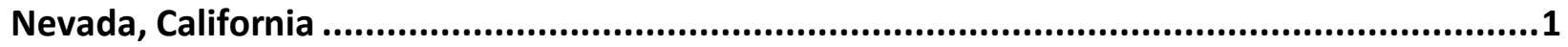

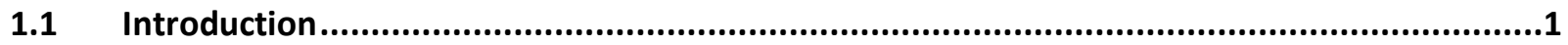

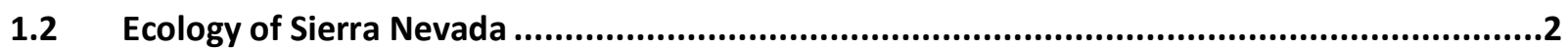

$1.3 \quad$ Fire Suppression Impacts and Implications .......................................................................

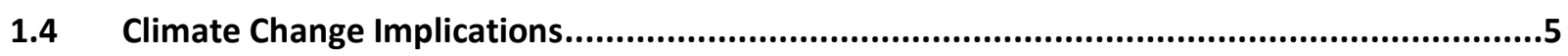

1.5 Management Effects/Implications .................................................................................6

1.6 Thesis Structure ….......................................................................................................

1.7 Conclusions..................................................................................................................

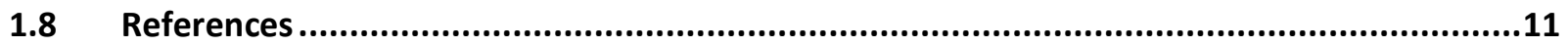

Chapter 2: Dendroclimatic analysis of Sierra Nevada mixed conifer species: comparison of growth responses to climate variables between small, medium, and large trees....................16

2.1 Introduction .....................................................................................................................16

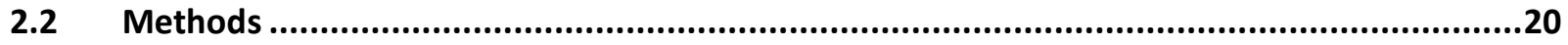

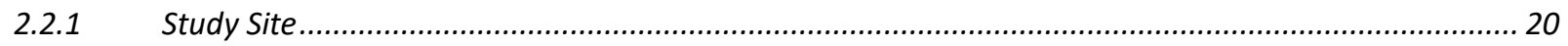

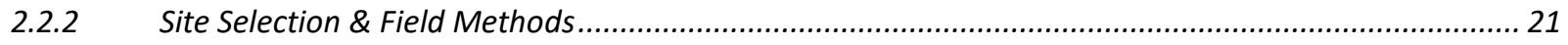

2.2.3 Laboratory Methods \& Dendrochronological Analysis ...............................................................22

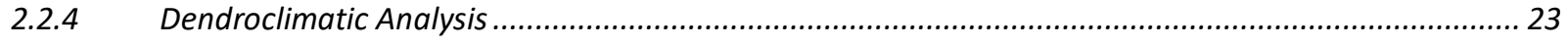

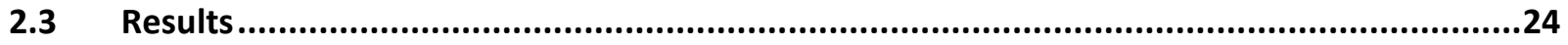

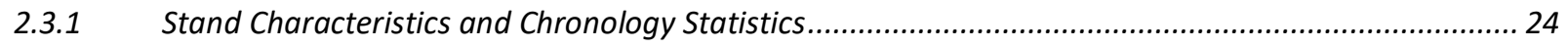

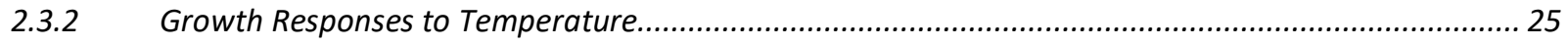

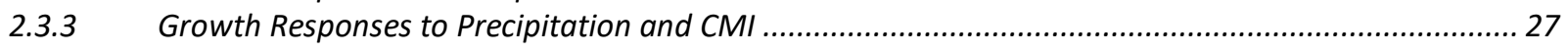

2.4 Discussion .................................................................................................29

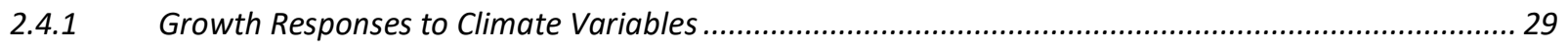

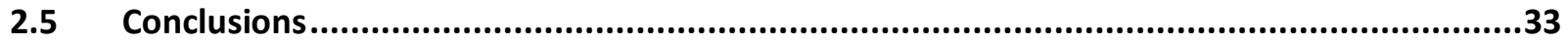

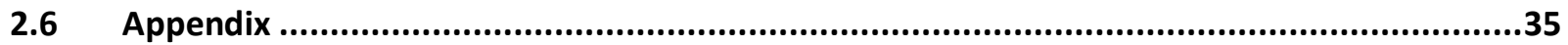

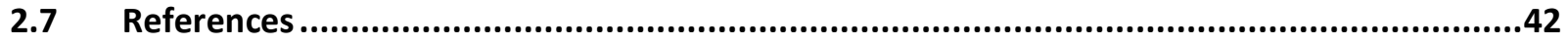

Chapter 3: Daily and stem cycle analysis of Pinus ponderosa and Pinus lambertiana: Radial release effects and climatic drivers of stem radial fluctuations ............................................46

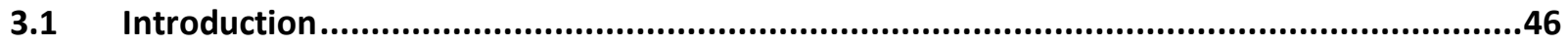

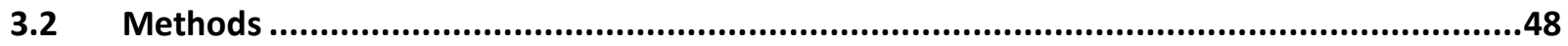




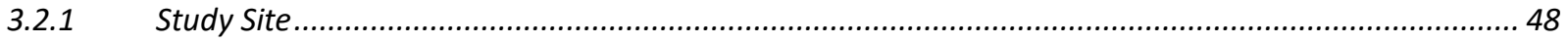

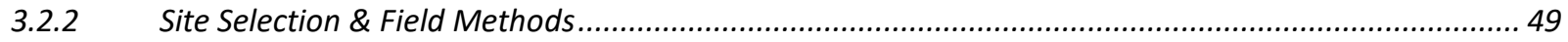

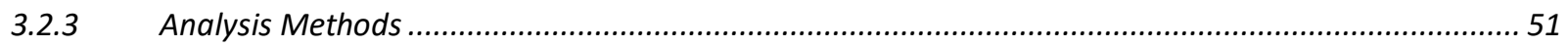

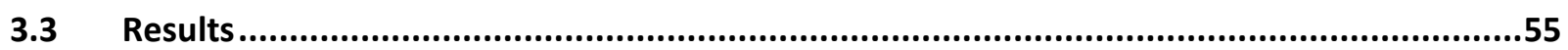

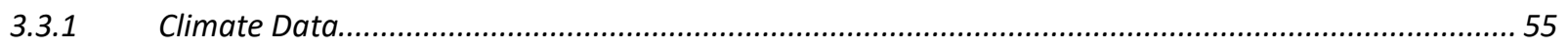

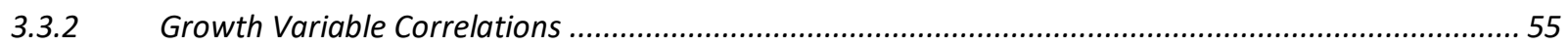

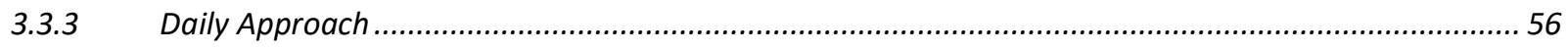

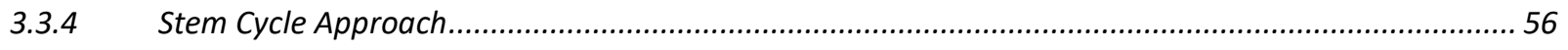

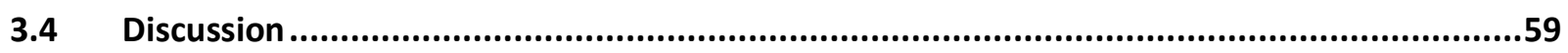

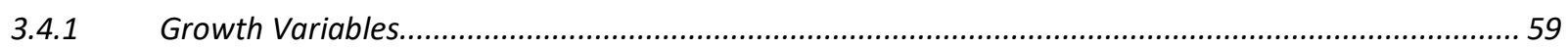

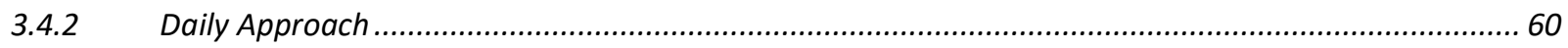

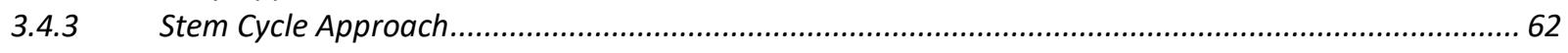

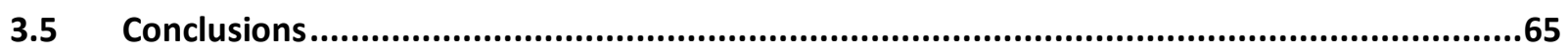

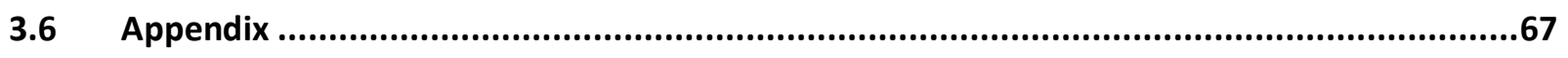

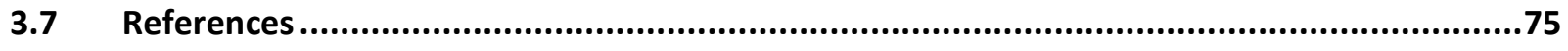

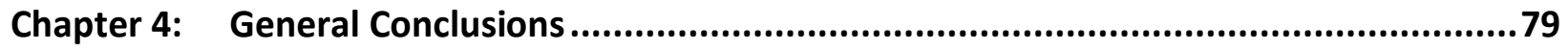




\section{List of Tables}

Table 2.1 Average basal area and quadratic mean diameter of the four main species studied and for all species combined. The "All" column total for basal area is slightly higher than the sum of the four main species due to small amounts of Jeffrey pine (Pinus jeffreyi) and/or red fir (Abies magnifica) in the sample plots.

Table 2.2 Statistics for the standardized tree ring chronologies for each species and DBH group.

Table 3.1 Summary table of trees that were measured with dendrometers. PIPO $=$ Pinus ponderosa (ponderosa pine) and PILA = Pinus lambertiana (sugar pine). The control treatment category did not have any radial thinning done; R30C0 had a constant radial thinning radius of $9.1 \mathrm{~m}$ regardless of $\mathrm{DBH}$; $\mathrm{R} 30 \mathrm{C} 2$ had the same treatment as $\mathrm{R} 30 \mathrm{C} 0$ but two competitor trees were left within the $9.1 \mathrm{~m}$ radius; lastly, the RD1.2 treatment radius was determined by multiplying the DBH in inches by 12 by 1.25 to get a radius (in feet) that was dependent on the $\mathrm{DBH}$.

Table 3.2 General descriptive statistics of the combined species-treatment groups. The mean plot radius for the control treatments is just for the measurement plots since there were no radial thinning treatments applied to them. The other mean plot radii were the actual mean radii of the radial thinning treatments applied.

Table 3.3 Significant correlations between growth variables. The underscore and number indicate a given phase ( 1 = contraction, 2 = expansion, 3 = radial increment). Magnitude is the absolute value of the difference between the highest and lowest normalized stem growth for a given phase, whereas duration is how long that phase lasted. Values considered significant if after 1000 bootstrapped correlations the 95\% confidence interval did not include zero. Light grey indicates a significant positive correlation between the variables whereas the black color indicates a significant negative correlation (mean correlation noted in cells with significant correlations). Hyphens (-) are noted in cells where comparisons were not made or to avoid duplicate correlations.

Table 3.4 Daily approach analysis. Significant correlation values after running 1000 bootstrapped correlations for each variable. Light grey indicates a significant positive correlation with daily amplitude and a given climate variable for that species-treatment group. Black color indicates a significant negative correlation. If there is a significant correlation, the mean correlation value is indicated within the cell. 70

Table 3.5 Stem cycle approach analysis. Significant correlation values after running 1000 bootstrapped correlations for each variable. Light grey indicates a significant positive correlation between the variables for that species-treatment group. Black color indicates a significant negative correlation. Mean correlation noted in cells with significant correlations. 


\section{List of Figures}

Figure 2.1 Map of study area; located in the southern portion of Lassen National Forest in northern California, southwest of Lake Almanor. Plots are indicated as black dots on the main map. Map courtesy of Johnson et al. (2017).

Figure 2.2 Standardized chronologies for the time frame of the dendroclimatological analysis (1969-2014). ABCO = Abies concolor, CADE = Calocedrus decurrens, PILA = Pinus lambertiana, PIPO = Pinus ponderosa. G1 = Diameter Group 1 (20.32 to < 40.64 $\mathrm{cm}$, small size), G2 = Diameter Group 2 (40.64 to $<60.96 \mathrm{~cm}$, medium size), G3 = Diameter Group 3 (> $60.96 \mathrm{~cm}$, large size). PIPO_G2 is not included because its Expressed Population Signal (EPS) value was too low for dendroclimatological analysis.

Figure 2.3 Species standardized chronologies with all DBH Groups combined for the time frame of the dendroclimatological analysis (1969-2014)....

Figure 2.4 Statistically significant $(p<0.05)$ growth responses to maximum temperature, minimum temperature, and mean temperature by species and diameter group and for each species as a whole (i.e., with all diameter groups combined). Darker coloring indicates a negative correlation with growth, while the lighter coloring indicates a positive correlation with growth. Numbers indicate the order of importance for that relationship, with 1 being the most important (according to the standardized partial regression coefficients). Explanatory climate variables expressed either for a monthly period or a 3-month seasonal period. $\mathrm{NS}=$ no significant variables in the model.

Figure 2.5 Statistically significant $(p<0.05)$ growth responses to precipitation and climate moisture index by species and diameter size group and for each species as a whole (i.e. with all diameter groups combined). Darker coloring indicates a negative correlation with growth, while the lighter coloring indicates a positive correlation with growth. Numbers indicate the order of importance for that relationship, with 1 being the most important (according to the standardized partial regression coefficients). Explanatory climate variables expressed either for a monthly period or a 3-month seasonal period.

Figure 3.1 Map of study area-located in the southern portion of Lassen National Forest in northern California, just southwest of Lake Almanor. Focal trees (plot centers) are indicated as black dots on the main map. Trees measured with dendrometers are randomly dispersed throughout the study area plots. Map courtesy of Johnson et al. (2017).

Figure 3.2 Example output of the actual dendrometer data stem cyclic phases for an individual sugar pine tree, 126R30 (A), and for a portion of the normalized dendrometer data showing stem cyclic phases of the PILA_R30C0 treatment group (B). Yellow indicates contraction (phase 1), orange indicates expansion (phase 2), and red indicates stem radial increment (phase 3 ). Stem radial increment occurs when the stem expands further than the previous maximum.

Figure 3.3 Chester RAWs weather station for the measurement period. Data shown here is from the time of the first dendrometer measurement to the last dendrometer measurement. 


\section{Chapter 1: Forest Conditions and Current Management Approaches in Northern Sierra Nevada, California}

\subsection{Introduction}

Human impacts such as fire suppression and inappropriate logging have led to a change in forest composition and structure to more shade-tolerant trees such as Abies concolor (white fir) and Calocedrus decurrens (incense cedar) in the Sierra Nevada region (Miller and Urban 2000; Taylor 2000; Smith et al. 2005; Beaty and Taylor 2008; Moghaddas et al. 2008). The forest understory was historically less dense, lacking the ladder fuels that are present today (Smith et al. 2005; Collins et al. 2011). Because of this increase in density and therefore increase in shading of the forest floor, shade-tolerant trees such as white fir and incense cedar can now outcompete the more shade-intolerant trees that have previously been a major component of these ecosystems. Presence of ladder fuels causes a more continuous supply of fuel which then promotes the movement of surface fire from the forest floor up into the canopy-turning what could have been a surface fire into a crown fire. These dense thickets of ladder fuels and increased stand densities leads to an increased risk of stand-replacing wildfires (Miller and Urban 2000; Stephens and Collins 2004; Schmidt et al. 2008; Van de Water and North 2010; Johnson et al. 2014).

Canopy cover affects the likelihood of crown fires to spread across the landscape as well as the ability for shade-tolerant/intolerant species to regenerate in the understories (Schmidt et al 2008). Therefore, canopy cover can be manipulated to decrease the spread of crown fires. It can also be manipulated to allow more light to favor the ingrowth of more shade-intolerant species that have grown in these forests in the period of pre-fire suppression. Also, canopy cover can affect decomposition rates because of the role it plays in the microclimate of the forest floor such as with moisture levels and temperature levels (Kim et al. 1996; Stephens and Moghaddas 2005). All of these factors highlight the value of utilizing thinning treatments to mitigate issues brought about by fire suppression. 


\subsection{Ecology of Sierra Nevada}

The historical fire regimes in much of the western United States are described as low intensity surface fires that burn approximately every 4 to 25 years (Graham at al. 2004). The dramatic shift/halt in historic fire regimes as a result of previous fire suppression has led to the increase in fuel loads across landscapes and therefore the increase in susceptibility of our forests to fires of high intensity and severity (Graham et al. 2004; Stephens and Collins 2004; Johnson et al. 2014; Knapp et al. 2017). This poses a significant risk to our current forests as well as the communities of people surrounding those forests.

Common tree species found in these mixed-conifer forests of the Sierra Nevada are Pinus ponderosa (Ponderosa pine), Pinus lambertiana (sugar pine), Abies concolor (white fir), Calocedrus decurrens (incense-cedar), Pseudotsuga menziesii (Douglas-fir), and Quercus kelloggii (California black oak) (Stephens 1998; Stephens and Collins 2004; Moghaddas and Stephens 2008). Since the first four species mentioned are researched in the subsequent chapters, additional information discussed will be regarding those species. Ponderosa pine is shade intolerant and has a wide range throughout the western United States and parts of Canada and Mexico, with the highest concentration in the United States being in California (Graham and Jain 2005). Ponderosa pine can be found growing in both moist and dry conditions and is known for its ability to survive low severity wildfires (Graham and Jain 2005). It also has thick bark that protects it from fire and germinates from seed which aids in regeneration after fire (Pawlikowski et al. 2019). In the Sierra Nevada, ponderosa pine puts on radial growth from mid-April to early September, and puts on half of its yearly radial growth in 47 days during the period of its highest growth rate (Fowells 1941). Sugar pine grows throughout much of the Pacific northwest, most notably in the Klamath and Siskiyou mountains and on western slopes of the Sierra Nevada and Cascade Range (Habeck 1992). Sugar pine has intermediate shade tolerance and is commonly found on multiple different sites ranging from moist, steep, north- and east-facing slopes to more mesic, south-facing slopes (Habeck 1992). 
Sugar pine puts on radial growth from mid-April to late August, and puts on half of its yearly radial growth in 46 days during the period of its highest growth rate (Fowells 1941). White fir is shade tolerant and, in California and surrounding states, can be found in multiple different growing conditions depending on its location and elevation (Zouhar 2001). White fir puts on radial growth from early May to mid-August, and completes half of its yearly radial growth within 44 days during the period of its highest growth rate (Fowells 1941). Incense-cedar is also shade tolerant; it can grow on a range of sites from shaded stream courses to exposed slopes and grows well on hot, dry sites (Tollefson 2008). Incense-cedar is commonly found on xeric sites in mixed conifer forests of California (Tollefson 2008). Incense cedar puts on radial growth from mid-April to late August, and puts on half of its yearly radial growth within just 39 days during the period of its highest growth rate (Fowells 1941). It is important to highlight that the dates previously mentioned from Fowells (1941) are averages and can fluctuate depending on climate variations from year-to-year. Analysis of ponderosa pine at different elevations indicated that the start of radial growth also tended to be delayed further at higher elevations (Fowell 1941). In general, temperature has been attributed as one of the main environmental factors controlling the start of conifer growth in the Sierra Nevada, while water availability is the main factor controlling the ending of the growing season (Royce and Barbour 2001). Of the coniferous species mentioned, ponderosa and sugar pine are the most drought tolerant, followed by incense cedar and white fir (Barbour et al. 2007; Pile et al. 2019).

\subsection{Fire Suppression Impacts and Implications}

Significantly altered present forest conditions compared to the pre-fire suppression period is largely attributed to the lack of fire in these Sierra Nevada ecosystems, since fire is one of the key ecosystem processes in these forests (Collins et al. 2011). One key change is a higher tree density and canopy cover associated with unburned forests (Collins et al. 2011). High severity forest fire causes forest fragmentation, wildlife habitat loss, increased erosion and 
sedimentation, altered post-fire seedling recruitment, changes in carbon sequestration, among many other ecosystem processes (Miller et al. 2009). A study in old-growth mixed-conifer forests of the southern Sierra Nevada suggests that pathogen- and insect-induced mortality is significantly higher in areas with high stand densities but is not higher for shade-tolerant species (such as white fir) (Smith et al. 2005). This suggests that increased stand densities can lead to changes in composition toward more shade-tolerant species not just from microclimatic factors but from pathogen- and insect-induced mortality as well. The study conducted by Smith et al. (2005) also suggested that there is an increase in old-tree mortality due to higher stand densities. Furthermore, Ritchie et al. (2008) observed an increase in old-tree mortality in unmanaged ponderosa pine stands of the Black Mountain experimental forest of northeastern California. Since snags are an important habitat for many wildlife species, it is important to also consider snag density changes due to fire suppression. Snag density has significantly increased since pre-fire suppression, while average snag size has significantly decreased (Knapp 2015). Though higher snag densities might sound better for wildlife, larger snags are preferred by many wildlife species—-therefore, fire suppression has essentially lowered the number of suitable snag trees for wildlife habitat (Knapp 2015).

The extent of high severity fires has notably increased since the 1980s for a large area of California and western Nevada (Miller et al. 2009). Mean and maximum fire size as well as the total area burned annually have all notably risen since the beginning of the 1980s and are now at or rising above values from those right before fire suppression became a national practice in the mid 1930s (Miller et al. 2009). On that same note, low vigor and increased stress due to competition for resources (i.e. from increased stand densities) has been linked to greater susceptibility to fire for many different tree species (Cocking et al. 2012).

Forest composition change over 39 years (from 1954/1961 to 1996) was studied in an oldgrowth mixed conifer forest in the northern Sierra Nevada and found that-over the last 39 years—stand density increased 39\% and stand basal area increased 15\% (Ansley and Battles 
1998). These changes were largely attributed to the canopy recruitment of white fir and continued growth and low mortality of Douglas-fir (Ansley and Battles 1998). These increased stand densities created lower light conditions that favored the encroachment of more shadetolerant species such as white fir. Encroachment of shade-tolerant species growing in the understory adds the component of ladder fuels into stands that historically had open understories. These ladder fuels now add the risk of understory fires being able to transition up into the crowns and create more intense and devastating fires (Schoennagel et al. 2004; Lyderson et al. 2013).

\subsection{Climate Change Implications}

Future climate was projected for the Sierra Nevada region by 11 GCMs (Global Climate Models) under two emission scenarios (SRES (Special Report on Emissions Scenario(s))): a higher emission scenario (A2) and a lower emission scenario (B1) (Maurer 2007). It was projected that, by $2071-2100$, temperatures will rise by an average of $3.7^{\circ} \mathrm{C}$ under $\mathrm{A} 2$ and $2.4^{\circ} \mathrm{C}$ under $\mathrm{B} 1$, with July temperatures rising most by $5^{\circ} \mathrm{C}$ for $\mathrm{A} 2$ and $3^{\circ} \mathrm{C}$ for $\mathrm{B} 1$ (Maurer 2007). Annual precipitation cannot be projected as broadly as annual temperatures, however. Higher magnitudes of increases in winter precipitation and decreases in spring precipitation are projected under $\mathrm{A} 2$ than $\mathrm{B} 1$, though the annual average precipitation does not differ much between both scenarios (Maurer 2007).

Climate change-related stress is a key component to consider when determining the resilience of certain species to changes in climate that can be associated with increased competition for resources. Climate change-related stressors such as decreased precipitation in the spring and increased temperature during the growing season may have differing effects on dominant trees compared to competitors such as shade-tolerant species like white fir. Johnson et al. (2017) found that poor growing conditions such as those previously mentioned tend to hurt 
competitors more than dominant trees, while positive growing conditions tended to help competitors more than dominant trees. This finding suggests that dominant pine trees that have been historically present in these forests may be more resilient to climate change effects than the newly establishing shade-tolerant competitors such as white fir and incense cedar (Johnson et al. 2017).

Changes in climate also have an impact on wildfire risk and behavior. When comparing fire risks under the $\mathrm{A} 2$ and $\mathrm{B} 1$ scenarios, the $\mathrm{A} 2$ scenario results in a greater increase in large fire probabilities (Westerling and Bryant 2008). Increases in fire risk for northern California were all positive and increasing with temperature, whereas the change in fire risk for southern California ranged from decreases of $-29 \%$ to increases of $28 \%$-which is attributed to differences in precipitation between the different emission scenarios (Westerling and Bryant 2008). It is important to note that—when comparing different global climate models and scenarios—-there is much more uncertainty in precipitation changes than there is for temperature changes in California, making it difficult to assess fire risk changes due to climate change driven precipitation changes (Westerling and Bryant 2008). The Hadley Centre and Canadian GCMs, used to estimate fire season severity in the middle of the next century, suggested that changes in season severity ratings (SSR) across the United States increase from a range of $10-50 \%$ (Flannigan et al. 2000). In general, all of these findings imply that fire severity on the landscape in the United States will likely increase due to climate change.

\subsection{Management Effects/Implications}

Most of the management associated with addressing the fuel build up issues due to fire suppression deal with varying thinning treatments, mastication treatments, and prescribed burns (Moghaddas et al. 2008; Schmidt et al. 2008; Johnson et al. 2014). In a study comparing different management effects, harvest of all trees up to 14 " diameter quickly restored multiple aspects of pre-fire suppression mixed conifer forest conditions (Miller and Urban 2000). In the 
same study, prescribed fire resulted in similar changes if they were sufficiently severe (Miller and Urban 2000). This brings about the idea that canopy cover treatments paired with prescribed burn treatments may be an effective management method to restore these ecosystems to their historic conditions.

Stands that have been altered due to fire suppression and inappropriate logging must also be managed to mitigate potential fire behavior from the increased stand densities and presence of ladder fuels, as well as the general buildup of fuels. Based on simulated fire behavior in the Southern Cascade Range of California, rate of spread, percent crown burned, heat released, and flame length were lowest for mechanical thin plus prescribed burn treatments, highest for just prescribed burn treatments, and intermediate for just mechanical thin treatments (Schmidt at al. 2008). This simulation suggests that mechanical thinning plus prescribed burn treatments would likely be most effective at minimizing high severity fire risks. 100 -hour fuels (fuels between 1 and 3 ") were higher in mechanical thin plus prescribed burn plots than in the controls, which was attributed to the prescribed burning not consuming all the 100 -hour fuels added by the mechanical thinning treatment-even though whole tree removal was used (Schmidt et al. 2008). This brings up the idea that mastication may be necessary in both the ponderosa pine plantations as well as the mixed-conifer forests to best minimize fuel loadingdepending how thorough thinning treatments and brush clean ups are. Crown scorch, bole char, and tree mortality (after simulated fire) was found to be lower in stands that were thinned and burned compared to stands that were only thinned (Raymond and Peterson 2005; Ritchie et al. 2007; Schmidt et al. 2008). In terms of area burned, the simulation determined that-overall— prescribed burn treatments alone decrease the area burned the most compared to the control, followed by the mechanical thin plus prescribe burn and then mechanical thinning alone (Schmidt et al. 2008). This does not suggest that mechanical thin plus prescribed burn treatments are the most effective at minimizing the extent of a fire, but mechanical thinning is 
needed to reduce the ladder fuels since prescribed burning alone may not be safe or able to reduce them-especially in areas with steep slopes.

Since large, old growth trees (often referred to as legacy trees) provide multiple ecosystem benefits such as wildlife habitat, carbon sequestration, and structural diversity, new thinning treatments designed to thin a certain radius around these trees are starting to be implemented in an attempt to improve vigor and reduce their mortality (Hood et al. 2018). In a study done by Hood et al. (2018), they found that, for legacy Pinus ponderosa (ponderosa pine) and Pinus jeffreyi (Jeffrey pine), radial thinning treatments that removed every tree less than 10 " dbh within the width of the legacy tree crowns were not sufficient enough to cause a substantial increase in basal area increment (BAI). This lack of increase in BAI was mainly attributed to the thinning area around the legacy trees being too small. They suggested that a larger thinning radius may increase legacy tree BAI more. However, there are other benefits to these thinning treatments in general than just increased growth. Thinning treatments may limit drought-induced mortality (Bradford and Bell 2017) and lower wildfire risk due to the creation of heterogenous canopy conditions (Hood et al. 2018; Fulé et al. 2012). Since bark beetles usually target weak/stressed trees, thinning treatments may even lower the likelihood of bark beetle attacks on these larger trees since the improved growing conditions created by freeing up resources via thinning would decrease their stress and likely make them less susceptible to bark beetle attacks (Bentz et al. 2010; Fettig et al. 2007). Though current methods attempting to improve vigor of these legacy trees is to thin a certain radius around them (i.e. Hood et al. 2018), there is little information on the specific radius that is best to thin around these trees and their effectiveness in the Sierra Nevada region. This brings up the importance of applying and studying different radial thinning treatments to try and build a basis of proper thinning radii to use to release these legacy trees effectively. 


\subsection{Thesis Structure}

The objective of Chapter 2 is to perform a dendroclimatic analysis to examine the effect of past climate on northern Sierra Nevada tree species (white fir, sugar pine, ponderosa pine, and incense cedar) and compare the growth responses of three diameter size classes to multiple climatic variables. This chapter will help to further expand our understanding of how small, medium, and large-sized trees responded to previous climate, as well as how shade tolerant and intolerant trees responded differently. This may shed light on what climate variables are driving growth the most between tree sizes as well as between shade tolerances - therefore shedding light on how the increased shade tolerant species composition in the northern Sierra Nevada may be affected by climate change.

Since there are a lack of studies in the northern Sierra Nevada which analyze the ideal radius for radial thinning treatments around legacy trees, one objective of Chapter 3 is to use dendrometer instruments to analyze sub-hourly stem fluctuations of ponderosa and sugar pines after multiple different radial thinning treatments to assess the short-term effects of these treatments. This will help to provide guidance earlier to managers as to what thinning radius, whether it be diameter-based or a fixed radius, may be best to use to improve tree health and vigor of the remaining legacy trees. The other objective of this study is to analyze the sub-hourly dendrometer data collected on the ponderosa and sugar pines within those varying radial thinning treatments to assess climatic drivers of hourly stem fluctuations. This will also provide managers with an idea as to how different radial thinning treatments can be used to affect the microclimates around the radially released legacy trees-as well as build our understanding of climate effects on daily stem variation in the northern Sierra Nevada region.

\subsection{Conclusions}

It is important that we mitigate these forest changes to protect our forests and people from experiencing larger and more frequent fires. This study will not only help to generate a basis for 
proper radii of radial thinning treatments, but it will help to build our understanding of how climate variables affect tree growth in the Sierra Nevada. This knowledge can be used to infer how climate change will affect tree growth in the future, as well as how we can alter climate variables via radial thinning treatments to create more ideal growing conditions for the legacy trees in the northern Sierra Nevada region. 
1.8 References 
Ansley, J.-A.S., Battles, J.J., 1998. Forest Composition, Structure, and Change in an OldGrowth Mixed Conifer Forest in the Northern Sierra Nevada. J. Torrey Bot. Soc. 125, 297 308.

Barbour, M.G., Keeler-Wolf, T., Schoenherr, A.A. (Eds.), 2007. Terrestrial Vegetation of California, Third Edit. ed. University of California Press.

Beaty, R.M., Taylor, A.H., 2008. Fire history and the structure and dynamics of a mixed conifer forest landscape in the northern Sierra Nevada, Lake Tahoe Basin, California, USA. For. Ecol. Manage. 255, 707-719. https://doi.org/10.1016/j.foreco.2007.09.044

Bentz, B.J., Regniere, J., Fettig, C.J., Hansen, E.M., Hayes, J.L., Nicke, J.A., Kelsey, R.G., Negron, J.F., and Seybold, S.J. 2010. Climate change and bark beetles of the western United States and Canada: direct and indirect effects. BioScience 60:602-613.

Cocking, M.I., Varner, J.M., Sherriff, R.L., 2012. California black oak responses to fire severity and native conifer encroachment in the Klamath Mountains. For. Ecol. Manage. 270, 2534. https://doi.org/10.1016/j.foreco.2011.12.039

Collins, B.M., Everett, R.G., Stephens, S.L., 2011. Impacts of fire exclusion and recent managed fire on forest structure in old growth Sierra Nevada mixed-conifer forests. Ecosphere 2. https://doi.org/10.1890/ES11-00026.1

Flannigan, M.D., Stocks, B.J., Wotton, B.M., 2000. Climate change and forest fires. Sci. Total Environ. 262, 221-229. https://doi.org/10.1016/S0048-9697(00)00524-6

Fowells, H., 1941. Seasonal Growth of Six Coniferous. J. For. 601-608.

Fryer, J. L. 2007. Quercus kelloggii. In: Fire Effects Information System, [Online]. U.S. Department of Agriculture, Forest Service, Rocky Mountain Research Station, Fire Sciences Laboratory (Producer). Available:

https://www.fs.fed.us/database/feis/plants/tree/quekel/all.html [2019, December 112019, December 11].

Fulé, P.Z., Crouse, J.E., Roccaforte, J.P., Kalies, E.L., 2012. Do thinning and/or burning treatments in western USA ponderosa or Jeffrey pine-dominated forests help restore natural fire behavior? For. Ecol. Manage. 269, 68-81. https://doi.org/10.1016/j.foreco.2011.12.025

Gersonde, R., Battles, J.J., O'Hara, K.L., 2004. Characterizing the light environment in Sierra Nevada mixed-conifer forests using a spatially explicit light model. Can. J. For. Res. 34, 1332-1342. https://doi.org/10.1139/X04-013

Graham, R.T., Jain, T.B., 2005. Ponderosa pine ecosystems, USDA Forest Service Gen. Tech. Rep. PSW-GTR-198 1-32.

Habeck, R. J. 1992. Pinus lambertiana. In: Fire Effects Information System, [Online]. U.S. Department of Agriculture, Forest Service, Rocky Mountain Research Station, Fire Sciences Laboratory (Producer). Available: https://www.fs.fed.us/database/feis/plants/tree/pinlam/all.html [2019, December 112019, December 11]. 
Hammett, E.J., Ritchie, M.W., Berrill, J.P., 2017. Resilience of California black oak experiencing frequent fire: Regeneration following two large wildfires 12 years apart. Fire Ecol. 13, 91103. https://doi.org/10.4996/fireecology.1301091

Hood, S.M., Cluck, D.R., Jones, B.E., Pinnell, S., 2018. Radial and stand-level thinning treatments: 15-year growth response of legacy ponderosa and Jeffrey pine trees. Restor. Ecol. 26, 813-819. https://doi.org/10.1111/rec.12638

Johnson, C., Chhin, S., Zhang, J., 2017. Effects of climate on competitive dynamics in mixed conifer forests of the Sierra Nevada. For. Ecol. Manage. 394, 1-12. https://doi.org/10.1016/j.foreco.2017.03.017

Johnson, D.W., Walker, R.F., Glass, D.W., Stein, C.M., Murphy, J.B., Blank, R.R., Miller, W.W., 2014. Effects of thinning, residue mastication, and prescribed fire on soil and nutrient budgets in a Sierra Nevada mixed-conifer forest. For. Sci. 60, 170-179. https://doi.org/10.5849/forsci.12-034

Kim, C., Sharik, T.L., Jurgensen, M.F., 1996. Canopy cover effects on mass loss, and nitrogen and phosphorus dynamics from decomposing litter in oak and pine stands in northern Lower Michigan. For. Ecol. Manage. 80, 13-20. https://doi.org/10.1016/03781127(95)03653-9

Knapp, E.E., 2015. Long-term dead wood changes in a Sierra Nevada mixed conifer forest: Habitat and fire hazard implications. For. Ecol. Manage. 339, 87-95. https://doi.org/10.1016/j.foreco.2014.12.008

Knapp, E.E., Lydersen, J.M., North, M.P., Collins, B.M., 2017. Efficacy of variable density thinning and prescribed fire for restoring forest heterogeneity to mixed-conifer forest in the central Sierra Nevada, CA. For. Ecol. Manage. 406, 228-241. https://doi.org/10.1016/j.foreco.2017.08.028

Long, J.W., Anderson, M.K., Quinn-davidson, L., Goode, R.W., Lake, F.K., Skinner, C.N., 2016. Restoring California black oak ecosystems to promote tribal values and wildlife. USDA For. Serv. Gen. Tech. Rep. 110.

Long, J.W., Goode, R.W., Gutteriez, R.J., Lackey, J.J., Anderson, M.K., 2017. Managing California Black Oak for Tribal Ecocultural Restoration. J. For. 115, 426-434. https://doi.org/10.5849/jof.16-033

Lydersen, J.M., North, M.P., Knapp, E.E., Collins, B.M., 2013. Quantifying spatial patterns of tree groups and gaps in mixed-conifer forests: Reference conditions and long-term changes following fire suppression and logging. For. Ecol. Manage. 304, 370-382. https://doi.org/10.1016/j.foreco.2013.05.023

Maurer, E.P., 2007. Uncertainty in hydrologic impacts of climate change in the Sierra Nevada, California, under two emissions scenarios. Clim. Change 82, 309-325. https://doi.org/10.1007/s10584-006-9180-9

McDonald, P., 1990. Quercus kelloggii Newb. Silvics North Am. 2, 661-671. 
Miller, C., Urban, D.L., 2000. Modeling the effects of fire management alternatives on Sierra Nevada mixed-conifer forests. Ecol. Appl. 10, 85-94. https://doi.org/10.1890/10510761(2000)010[0085:MTEOFM]2.0.CO;2

Miller, J.D., Safford, H.D., Crimmins, M., Thode, A.E., 2009. Quantitative evidence for increasing forest fire severity in the Sierra Nevada and southern Cascade Mountains, California and Nevada, USA. Ecosystems 12, 16-32. https://doi.org/10.1007/s10021-0089201-9

Miller, R.E., Colbert, S.R., Morris, L.A., 2004. Effects of heavy equipment on physical properties of soils and on long-term productivity: A review of literature and current research. NCASI Tech. Bull.

Moghaddas, E.E.Y., Stephens, S.L., 2008. Mechanized fuel treatment effects on soil compaction in Sierra Nevada mixed-conifer stands. For. Ecol. Manage. 255, 3098-3106. https://doi.org/10.1016/j.foreco.2007.11.011

Moghaddas, J.J., York, R.A., Stephens, S.L., 2008. Initial response of conifer and California black oak seedlings following fuel reduction activities in a Sierra Nevada mixed conifer forest. For. Ecol. Manage. 255, 3141-3150. https://doi.org/10.1016/j.foreco.2007.11.009

Pawlikowski, N.C., Coppoletta, M., Knapp, E., Taylor, A.H., 2019. Spatial dynamics of tree group and gap structure in an old-growth ponderosa pine-California black oak forest burned by repeated wildfires. For. Ecol. Manage. 434, 289-302. https://doi.org/10.1016/j.foreco.2018.12.016

Pile, L.S., Meyer, M.D., Rojas, R., Roe, O., Smith, M.T., 2019. Drought impacts and compounding mortality on forest trees in the southern sierra nevada. Forests 10. https://doi.org/10.3390/f10030237

Raymond, C.L., Peterson, D.L., 2005. Fuel treatments alter the effects of wildfire in a mixedevergreen forest, Oregon, USA. Can. J. For. Res. 35, 2981-2995. https://doi.org/10.1139/x05-206

Ritchie, M.W., Skinner, C.N., Hamilton, T.A., 2007. Probability of tree survival after wildfire in an interior pine forest of northern California: Effects of thinning and prescribed fire. For. Ecol. Manage. 247, 200-208. https://doi.org/10.1016/j.foreco.2007.04.044

Ritchie, M.W., Wing, B.M., Hamilton, T.A., 2008. Stability of the large tree component in treated and untreated late-seral interior ponderosa pine stands. Can. J. For. Res. 38, 919-923. https://doi.org/10.1139/X07-242

Royce, E.B., Barbour, M.G., 2001. Mediterranean climate effects. I. Conifer water use across a Sierra Nevada ecotone. Am. J. Bot. 88, 911-918. https://doi.org/10.2307/2657044

Schmidt, D.A., Taylor, A.H., Skinner, C.N., 2008. The influence of fuels treatment and landscape arrangement on simulated fire behavior, Southern Cascade range, California. For. Ecol. Manage. 255, 3170-3184. https://doi.org/10.1016/j.foreco.2008.01.023

Schoennagel, T., Veblen, T.T., Romme, W.H., 2004. The Interaction of Fire, Fuels, and Climate across Rocky Mountain Forests. Bioscience 54, 661. https://doi.org/10.1641/0006- 
3568(2004)054[0661:tioffa]2.0.co;2

Smith, T.F., Rizzo, D.M., North, M., 2005. Patterns of mortality in an old-growth mixed-conifer forest of the southern Sierra Nevada, California. For. Sci. 51, 266-275.

https://doi.org/10.1093/forestscience/51.3.266

Stephens, S.L., 1998. Evaluation of the effects of silvicultural and fuels treatments on potential fire behaviour in Sierra Nevada mixed-conifer forests. For. Ecol. Manage. 105, 21-35. https://doi.org/10.1016/S0378-1127(97)00293-4

Stephens, S.L., Collins, B.M., 2004. Fire regimes of mixed confer forests in the North-Central Sierra Nevada at multiple scales. Northwest Sci. 78, 12-23.

Stephens, S.L., Moghaddas, J.J., 2005. Silvicultural and reserve impacts on potential fire behavior and forest conservation: Twenty-five years of experience from Sierra Nevada mixed conifer forests. Biol. Conserv. 125, 369-379.

https://doi.org/10.1016/j.biocon.2005.04.007

Taylor, A.H., 2000. Fire regimes and forest changes in mid and upper montane forests of the southern Cascades, Lassen. J. Biogeogr. 27, 87-104.

Tollefson, Jennifer E. 2008. Calocedrus decurrens. In: Fire Effects Information System, [Online]. U.S. Department of Agriculture, Forest Service, Rocky Mountain Research Station, Fire Sciences Laboratory (Producer). Available: https://www.fs.fed.us /database/feis/plants/tree/caldec/all.html [2019, December 112019, December 11].

Uchytil, Ronald J. 1991. Pseudotsuga menziesii var. menziesii. In: Fire Effects Information System, [Online]. U.S. Department of Agriculture, Forest Service, Rocky Mountain Research Station, Fire Sciences Laboratory (Producer). Available:

https://www.fs.fed.us/database/feis/plants/tree/psemenm/all.html [2019, December 112019, December 11].

Van de Water, K., North, M., 2010. Fire history of coniferous riparian forests in the Sierra Nevada. For. Ecol. Manage. 260, 384-395. https://doi.org/10.1016/j.foreco.2010.04.032

Westerling, A.L., Bryant, B.P., 2007. Climate change and wildfire in California. Clim. Change 87. https://doi.org/10.1007/s10584-007-9363-z

Zouhar, Kris. 2001. Abies concolor. In: Fire Effects Information System, [Online]. U.S. Department of Agriculture, Forest Service, Rocky Mountain Research Station, Fire Sciences Laboratory (Producer). Available:

https://www.fs.fed.us/database/feis/plants/tree/abicon/all.html [2019, December 112019, December 11]. 


\section{Chapter 2: Dendroclimatic analysis of Sierra Nevada mixed conifer species: comparison of growth responses to climate variables between small, medium, and large trees}

\subsection{Introduction}

Climate change is expected to alter many different aspects of the current climate, with temperatures being one of the most notable changes especially in the Mediterranean region of northern California. It is expected that global surface temperatures will rise under all future climate change emission scenarios, otherwise called Representative Concentration Pathways (RCPs) (IPCC 2013). Relative Concentration Pathways are broken down by the IPCC into different intensity emission scenarios: RCP2.6 (lowest emission scenario), RCP4.5, RCP6.0, and RCP8.5 (highest emission scenario) (IPCC 2013). Relative to 1986-2005, temperatures will likely rise between $0.3^{\circ} \mathrm{C}$ and $0.7^{\circ} \mathrm{C}$ by the $2016-2035$ time period. For the lowest emission RCP2.6 scenario, global surface temperatures are likely to rise an average of $1.0^{\circ} \mathrm{C}$ in both the 2046-2065 and 2081-2100 time periods (IPCC 2013). In contrast-for the highest emission

scenario (RCP8.5) — global surface temperatures are likely to rise even more with an average of $2.0^{\circ} \mathrm{C}$ and $3.7^{\circ} \mathrm{C}$ in the $2046-2065$ and $2081-2100$ time periods, respectively (IPCC 2013). These temperature increases, paired with the lack of any distinct changes in precipitation patterns projected to occur in California in the future (Luers et al. 1990), may be harmful to the future health of California's forests. In terms of precipitation changes, one climate model projects slightly wetter winters, while another projects slightly drier winters (Luers et al. 1990). A cascading effect on forest ecosystems reliant on spring moisture from snowpack melting may also occur due to earlier spring melting and general loss of snowpack likely to occur under all emission scenarios (Luers et al. 1990). On top of this possible domino effect from earlier snowmelt, if temperatures rise into the medium warming range, the risk of wildfires occurring in California could increase by as much as 55\%_almost double that of the lower warming range (Luers et al. 1990). While there are many risks and concerns regarding a future changing 
climate, mitigating these threats to our ecosystems requires analyzing and managing multiple facets of our natural resources_-including analyzing previous effects of climate variables on tree growth. Doing so can provide insight on how trees may respond to these changes in the future, and how we can manage our forests to be best suited for future conditions.

Previous research in northern California that looked at the growth responses of trees between 15 and $92 \mathrm{~cm}$ in DBH found, in general, winter precipitation (positive correlation) and summer temperatures (negative correlation) were the most important predictors of annual ring width variation for the six coniferous species studied (Pinus ponderosa, Pinus lambertiana, Pseudotsuga menziesii, Abies concolor, Abies magnifica, and Calocedrus decurrens) (Yeh and Wensel 2000). Another study, conducted in Plumas County in the northern Sierra Nevada region, looked at the same coniferous trees (except Abies magnifica) but only for DBHs greater than $76 \mathrm{~cm}$ (Bigelow et al. 2014). This study found that higher minimum winter temperatures (positive correlation) was one of the most important predictor variables followed by higher maximum summer temperatures (negative correlation) and log transformed precipitation of the current year or the year prior (positive correlation) (Bigelow et al. 2014). Interestingly, a study done in the Mediterranean climate region of Italy on Douglas-firs with an average DBH of $73 \mathrm{~cm}$ had similar findings in which growth was negatively correlated with maximum temperatures in July of the current year and October of the previous year (Castaldi et al. 2020). The Castaldi et al. (2020) study also had a similar finding to Bigelow et al. (2014) in which growth was positively correlated with winter temperatures of the current year of growth. Since the northern Sierra Nevada region of California is also in a Mediterranean climate, the results from the study done in Italy being similar to the results from the California studies may not be surprising. Research in other areas which compiled data from many temperate regions found that trees responded positively to increased summer temperatures (Way and Oren 2010), which is generally not the case for the Sierra Nevada and Mediterranean regions (Bigelow et al. 2014; Castaldi et al. 2020; Yeh and Wensel 2000). This is likely because the summers in Mediterranean climates are 
usually much drier with most of the yearly precipitation occurring in the winters (Bigelow et al. 2014; Castaldi et al. 2020). Therefore, due to different climate patterns and tree species (among other factors), it is difficult to assert that growth responses in one climate can occur in another.

It has been found that large and small trees may have different responses to climate variables, whether it be age dependent or size dependent (Mérian and Lebourgeois 2011; Vieira et al. 2009). Furthermore, younger trees may exhibit more erratic growth since they are usually being influenced by a higher number of environmental factors in the understory (Chhin et al. 2008a; Copenheaver and Abrams 2003). Szeicz and MacDonald (1994) found that, in the western Northwest Territories, Canada, older Picea glauca (white spruce) responded negatively to previous summer temperatures while the younger trees did not. They attributed general differences in growth responses to physiological changes that occur as trees age, such as changes in root, shoot, and cambial growth patterns (Szeicz and MacDonald 1994). This change in growth patterns may be causing the larger trees to be more dependent and affected by previous years growing conditions. For example, large trees have a larger stem and root system than small trees (and therefore more tissue for storing nutrients) so they may be more negatively affected if previous summer conditions inhibit their ability to grow and store as much nutrients for the following year. In addition, respiration demands generally increase as trees age (West 2020), so higher temperatures would amplify those increased respiration demands-i.e. causing more photosynthate to be used for respiration and therefore less photosynthate for storage. An increased rate of respiration is expected in more exposed higher canopy leaves (Pallardy 2008), which older/larger trees would likely contain. This raises the question as to whether smaller trees will respond as strongly as larger trees do to the climate variables often looked at in dendroclimatology.

Mérian and Lebourgeois (2011) found that, in the Mediterranean climate region of France, shade tolerant species (Abies alba and Fagus sylvatica) had a significantly different response to summer drought between small and large trees, with large trees being more 
affected by summer drought periods. They attributed this occurrence to the possible increase in canopy heterogeneity in areas with more shade tolerant species. In other words, since shade tolerant species can persist better in low light, there may be larger gaps between the upper, large diameter, and lower, small diameter crowns_causing the smaller diameter trees to be protected more due to differences in microclimatic conditions such as buffered temperature variations (Mérian and Lebourgeois 2011). Vieira et al. (2009), a study which was also done in a Mediterranean climate (Portugal), found that earlywood (i.e. springwood) of young trees was more sensitive to climate influence while the older trees were more sensitive in the latewood (i.e. summerwood) portion of growth. Though these two studies found differences between small and large/young and old trees in Mediterranean climates, this type of direct comparison study is still yet to be conducted in the northern Sierra Nevada region of California.

All of these studies mentioned were dendrochronology-based studies; more specifically, they were dendroclimatological studies. Dendrochronology is the method of assigning calendar years to specific tree rings by using crossdating techniques which help to identify and match up distinct patterns and similarities between two cores of the same tree and/or across multiple trees. Doing so better assures that counting errors as well as errors associated with missing and false rings do not occur (Yamaguchi 1991). Dendroclimatology is a subdiscipline of dendrochronology in which tree rings are compared with past climate to help determine how historic climate factors impacted growth. Dendroclimatology principles can also be expanded further to project how trees will respond to future climate projections based on how they responded historically (Chhin et al. 2008b). The use of these dendrochronology and dendroclimatology principles helps to build our understanding of tree responses to climate as well as how trees may respond to a future changing climate. Knowing how trees may respond to future climate can help to build better adaptive management plans that can try to account for those future changes. 
The objective of this study is to examine the effect of climate on northern Sierra Nevada tree species (white fir, sugar pine, ponderosa pine, and incense cedar) and compare the growth responses of three diameter size classes to different climatic variables. Considering the findings of studies conducted in other Mediterranean climate regions, I hypothesize that 1) species in the largest diameter group will respond differently to climate variables than the smallest diameter

group, especially for shade tolerant species and 2) large trees will show more lagged responses to growth due to their ability to store more food reserves than smaller trees.

\subsection{Methods}

\subsubsection{Study Site}

The study took place in the Lassen National Forest in the northern Sierra Nevada range of California at an average elevation of $1530 \mathrm{~m}$ (Figure 2.1). The Lassen National Forest is in the M261 Sierran Steppe-Mixed Forest-Coniferous Forest-Alpine Meadow Province ecoregion (Bailey 1994). This region of California is described as having warm, dry summers and cool, moist winters with most of the yearly precipitation generally happening in the winter (between October and March). Also, most precipitation happening at higher elevations in the winter comes in the form of snow and becomes an important resource for moisture as snow melts during the growing season (Yeh and Wensel 2000). The main soils found in this region are ultisols on mountain slopes with humid air, dry alfisols at lower elevations, and entisols in the narrow floodplains and alluvial fans of the valley (USDA Forest Service 1999). The most common tree species encountered were white fir (Abies concolor - ABCO), followed by sugar pine (Pinus lambertiana - PILA), ponderosa pine (Pinus ponderosa - PIPO), and incense cedar (Calocedrus decurrens - CADE). Ponderosa pine, sugar pine, and incense cedar all start their radial growth around mid-April and continue to put on radial growth for around 147, 129, and 136 days, respectively (Fowells 1941). White fir starts radial growth slightly later around early May and continues to put on radial growth for around 108 days (Fowells 1941). Ponderosa pine 
is the most shade intolerant, sugar pine has intermediate shade tolerance, incense cedar is shade tolerant, and white fir is the most shade tolerant of these species. The stands in the study area have an uneven-aged structure. In general, temperature has been attributed as one of the main environmental factors controlling the start of conifer growth in the Sierra Nevada, while water availability is the main factor controlling the ending of the growing season (Royce and Barbour 2001).

\subsubsection{Site Selection \& Field Methods}

The study sites were selected based on them containing an old-growth pine which was defined as having a breast height diameter of at least $63.5 \mathrm{~cm}$. A total of 40 plots were selected for the study; 25 of those plots had an old-growth sugar pine as the plot center and 15 plots had an old-growth ponderosa pine as the plot center. Within each of the measurement plots, the $\mathrm{DBH}$ and species of all trees were recorded. For every tree in the plot, a single core was taken at stump height $(0.5 \mathrm{~m})$ perpendicular to the direction of the slope to avoid compression wood (Speer 2010). For each of the "plot center" trees and their two key competitors, a second core was taken opposite the first core at the same height. It is important to note that Johnson et al. (2017) used the data and cores collected on the center and competitor trees to analyze how the growth of the center and competitor trees differed based on both the competition index and different climate variables. This current study is also using those cores from the center and competitor trees, but it is using the additional singular cores taken on all the other trees to analyze and compare growth responses to climate fluctuations between and within small (20.32 to $\leq 40.64 \mathrm{~cm})$, medium $(40.64$ to $\leq 60.96 \mathrm{~cm})$, and large (greater than $60.96 \mathrm{~cm}$ ) sized trees of the four species previously mentioned. 


\subsubsection{Laboratory Methods \& Dendrochronological Analysis}

To analyze the growth responses to climate and compare between different species and diameter groups, cores were separated out by species and diameter at breast height (DBH) ranges into 12 distinct groups. Groups were first separated into the 4 main tree species: Abies concolor (ABCO), Calocedrus decurrens (CADE), Pinus lambertiana (PILA), and Pinus ponderosa (PIPO). The few Abies magnifica and Pinus jeffreyi that were encountered were grouped with Abies concolor and Pinus ponderosa, respectively. Groups were then further broken down by DBH, herein referred to as Diameter Groups. Diameter Group 1 (i.e., small diameter size) ranged from 20.32 to $\leq 40.64 \mathrm{~cm}$, Group 2 (i.e., medium diameter size) ranged from 40.64 to $\leq 60.96 \mathrm{~cm}$, and Group 3 (i.e., large diameter size) was anything greater than $60.96 \mathrm{~cm}$. Diameter Groups were created by referencing the thinning guidelines used for the project area, which specified to keep all healthy pines greater than $40.64 \mathrm{~cm}$ within the radial release treatments and to center the radial release treatments around the healthiest pine tree greater than $60.96 \mathrm{~cm}$ in each plot (John Zarlengo, USDA Forest Service, personal communication). These guidelines were established to prevent the harvesting of the healthy medium-sized trees as well as to apply the thinning treatments around the healthy larger pine trees. Using these two criteria (species and DBH), 12 distinct groups were created; for example, Abies concolor was separated out into ABCO_G1, ABCO_G2, and ABCO_G3, no matter what plot the cores were initially in (since all plots were in the same general area).

Collected cores were dried in the lab and then mounted, sanded, and cross-dated using standard dendrochronological methods as in Speer (2010). Cross-dating was done by comparing and matching up ring width patterns (primarily narrow rings) using the list method for each species-diameter group (Yamaguchi 1991). Once visual cross-dating was done as accurately as possible, ring widths were measured in CooRecorder and then cross-dating accuracy was examined and further improved using program COFECHA (Holmes 1983). After cross-dating was finished, ring widths from every species-diameter group were then 
standardized in ARSTAN using the same standardization technique when possible to remove any noise from competition and other non-climatic factors such as age-related growth declines. Ring widths for all trees within diameter Group 1 and Group 2 were standardized using a negative exponential distribution with autocorrelation removed. Group 3 trees (ABCO_G3, CADE_G3, and PILA_G3) were standardized using a negative exponential distribution while PIPO_G3 was standardized using an 80-year cubic smoothing spline. It is important to note that PIPO_G2 was not analyzed for growth responses to climate due to it having much lower than the ideal 0.85 Expressed Population Signal (EPS value) (Briffa and Jones 1990). This EPS value is the benchmark for chronology signal strength and the time frame having this EPS value is considered to have a reliably strong chronology signal. For the small and medium diameter groups, the EPS value threshold was lowered because these size classes likely exhibit a weaker stand-wide signal since they may be more influenced by microsite factors (Kosiba et al. 2017). Since we are investigating growth-climate relationships and not trying to reconstruct past climate, this is an acceptable EPS value threshold for the smaller trees (Kosiba et al. 2017). Therefore, 11 of the 12 groups having an EPS value greater than 0.80 (and 0.85 for the large diameter group) were used for further analysis.

\subsubsection{Dendroclimatic Analysis}

To analyze growth responses to climate variables, long-term weather data for the geographic centroid of all plots (Lat 40.1900, Long -121.3110) were gathered from the PRISM Climate Group at Oregon State University (Daly et al. 2008) for the timeframe of the dendroclimatological analysis $(1969-2014)$. Specific data collected for analyses were the following primary climatic variables: minimum temperature (MIT), maximum temperature (MAT), mean temperature (MET), and precipitation (PPT). These variables were then used to calculate a secondary climate variable, climate moisture index (CMI) so that precipitation and temperature could be combined to express the moisture regime of the area (Hogg 1997). Each monthly 
variable was also converted into 3-month seasonal scales by averaging the temperature variables and summing up the precipitation and climate moisture index variables for the respective three-month periods. A regression model was then created for each speciesdiameter group's growth response to each of the climatic variables (monthly and 3-month seasonal scales) using an RScript program developed by Chhin et al. (2008b). This program utilizes a stepAIC function which prefers models that minimize Akaike's Information Criteria (AIC) values and penalizes models with excessive predictor variables (Chhin et al. 2008b). More specifically, variables were only included in a model if they lowered the AIC value by at least 2 when included (Akaike 1974). Using the program developed by Chhin et al. (2008b), growth responses to each of the climatic variables were analyzed from April of the previous year (t-1) through October of the current year $(\mathrm{t})$. The significant variables included in the regression models were then ranked based on their standardized $(\beta)$ partial regression coefficients; in this case, variables with the highest absolute value coefficient were ranked number one (Zar 1999).

\subsection{Results}

\subsubsection{Stand Characteristics and Chronology Statistics}

The overall average basal area $\left(\mathrm{m}^{2} / \mathrm{ha}\right)$ of the study area was $58.27 \mathrm{~m}^{2} / \mathrm{ha}$, with sugar pine contributing the most $\left(20.47 \mathrm{~m}^{2} /\right.$ ha), followed by white fir $\left(18.11 \mathrm{~m}^{2} / \mathrm{ha}\right)$, ponderosa pine (13.87 $\left.\mathrm{m}^{2} / \mathrm{ha}\right)$, and incense-cedar (5.48 $\left.\mathrm{m}^{2} / \mathrm{ha}\right)$ (Table 2.1). The $0.34 \mathrm{~m}^{2} /$ ha difference in overall average basal area from the sum of the four main species was due to small amounts of Jeffrey pine (Pinus jeffreyi) and/or red fir (Abies magnifica) in the sample plots. The overall quadratic mean diameter of the study area was $50.99 \mathrm{~cm}$, with sugar pine being the largest $(78.89 \mathrm{~cm})$, followed by ponderosa pine $(65.14 \mathrm{~cm})$, incense cedar $(45.02 \mathrm{~cm})$, and white fir $(37.4 \mathrm{~cm})$ (Table 2.1). The average ring-width (standard deviation in parenthesis) for ABCO_G1, G2, and G3 was $1.893 \mathrm{~mm}(0.754), 2.462 \mathrm{~mm}$ (0.966), and $2.714 \mathrm{~mm}$ (1.192), respectively. The average ring-width for CADE_G1, G2, and G3 was $1.627 \mathrm{~mm}$ (0.799), $1.753 \mathrm{~mm}$ (0.857), and $2.165 \mathrm{~mm}$ 
(1.179), respectively. The average ring-width for PILA_G1, G2, and G3 was $1.924 \mathrm{~mm}(0.768)$, $3.280 \mathrm{~mm}$ (0.878), $3.039 \mathrm{~mm}$ (1.444), respectively. The average ring-width for PIPO_G1, G2, and G3 was $2.434 \mathrm{~mm}$ (0.893), $2.624 \mathrm{~mm}$ (1.031), and $2.182 \mathrm{~mm}$ (1.015), respectively.

The average percentage of missing rings in a species and diameter group was $0.1806 \%$, with some groups having no missing rings, and the highest percentage of missing rings being $0.4422 \%$ (Table 2.2 ). Groups having no missing rings usually had a smaller number of trees. All groups reached an EPS value of 0.80 by 1969 (except PIPO_G2 which was excluded from analyses); most groups reached an EPS value of 0.85 by 1969 , except for CADE_G2 and PILA_G2 which maxed out at 0.803 and 0.830 , respectively. Mean sensitivity values ranged between 0.1165 and 0.2928 , with 10 out of the 11 groups being between 0.1165 and 0.1949 . Intercore correlation values were slightly numerically different between the $3 \mathrm{DBH}$ groups. The average intercore correlation value for DBH Group 1 was 0.252, while DBH Group 2 was 0.340, and DBH Group 3 was 0.345. Standardized chronologies are visually represented in Figures 2.2 and 2.3. Some key years of growth reduction (relative to the surrounding years) that can be seen in those figures are in 1977, 1985, and 2001. The most apparent and drastic growth reduction of those years, however, is in 1977 in which very narrow and missing rings were most commonly found.

\subsubsection{Growth Responses to Temperature}

All growth responses to maximum temperature were negative-except for PILA_G1 which responded positively to max temperature in April of the prior year (t-1) (Figure 2.4A). In general, there was a more apparent response to maximum temperature from species of diameter group 3 (largest diameter group). Most species-diameter groups responded negatively to maximum temperatures around summer to fall of the current year (if they did respond to maximum temperature), with the largest diameter group showing more of a lagged response to max temperatures in summer to early fall of the previous year. Both ABCO and PILA in diameter 
group 1 (smallest diameter group) responded negatively to maximum temperatures in June of the current year (t). A negative correlation with maximum temperature in July of the previous year ( $\mathrm{t}-1)$ was the only predictor variable for CADE_G1, and no predictor variable was found for PIPO_G1. Species in diameter group 2 had a very similar response to maximum temperatures compared to diameter group 1, however, no positive correlations were found in this group. The main differences between these diameter groups was that ABCO_G2 responded negatively to maximum temperatures for the May-July seasonal period (t) instead of just June (t), and PILA_G2 responded negatively to maximum temperatures in April ( $\mathrm{t}$ ) instead of June (t). Species in diameter group 3 had much different responses to maximum temperature. All species in diameter group 3, except ABCO_G3, responded negatively to maximum temperatures in late summer to fall of the current year (with varying importance). The only growth response from ABCO_G3 was a negative response to maximum temperatures in January-March of the current year. Also, more of a lagged response to maximum temperatures was seen from species in diameter group 3, in which they responded negatively to maximum temperatures in varying months throughout the year prior. Responses from each species with all diameter groups combined (i.e. denoted by “_ALL") tended to follow the same pattern of diameter group 3 more so than the other diameter groups.

More of a coherent trend across all groups can be observed for the growth responses to minimum temperatures (Figure 2.4 B). Most species and diameter groups responded negatively to minimum temperatures around early summer to early fall of the current year. However, more of a 3-month seasonal response to summer temperatures can be seen for species in diameter group 3, specifically ABCO_G3 and PILA_G3. Again, a lagged response was more apparent in diameter group 3 than the other diameter groups—with ABCO_G3, CADE_G3, and PILA_G3 responding negatively to minimum temperatures in the 3-month seasonal period of JulySeptember of the previous year $(\mathrm{t}-1)$. Perhaps one of the most coherent responses to minimum temperatures from all diameter groups was the positive response to minimum temperatures in 
the winter leading up to the current year of growth. Most of these positive responses can be seen from November (t-1) to January (t). Something else that stands out in this figure is the positive response to minimum temperatures in April (t-1) for PILA_G1 and in June (t-1) for PILA_G2. When all diameter groups are combined for each species, it is clear that increasing minimum winter temperatures had a positive influence on growth of all species in at least some portion of the winter months leading up to the current growing season. As seen in the maximum temperature figure (Figure 2.4 A), CADE_ALL and PIPO_ALL also exhibit that lagged negative response to minimum temperatures in July-September ( $\mathrm{t}-1)$ and May (t-1), respectively.

Mean temperatures had a very similar effect on growth as minimum temperatures, but no coherent response was seen in the winter months (Figure $2.4 \mathrm{C}$ ). In general, species from all diameter groups responded negatively to mean temperatures in summer to early fall of the current year. However, more of a trend arises when looking at mean temperatures in which species in diameter group 1 responded negatively to mean temperatures in June (t) whereas species in diameter group 3 responded negatively more so in the latter parts of the summer to early fall. As seen in the other temperature variables, a lagged response was more apparent from species in diameter group 3. Most of the same growth trends carried over when diameter groups were combined, but the lagged response became less apparent again.

\subsubsection{Growth Responses to Precipitation and CMI}

Nearly all growth responses to precipitation were positive (Figure $2.5 \mathrm{~A}$ ). The only negative response to precipitation was from PILA_G2 in which it responded negatively to precipitation in the June-August seasonal period of the previous year (t-1). This variable, however, was the least important predictor variable for PILA_G2 growth. In general, positive responses to precipitation can be observed between early fall of the previous year and spring of the current year. ABCO_G1 responded positively to precipitation in December-February (t) and September-October (t-1). CADE_G1 responded positively to precipitation only in February (t). 
PILA_G1 responded positively to precipitation in January-March (t) followed in importance by May (t). PIPO_G1 responded positively and strongest to precipitation in October ( $\mathrm{t}-1)$ followed by April ( $\mathrm{t})$. Species in diameter group 2 had a fairly similar pattern of responses. However, PILA_G2 did have a negative response to precipitation in the June-August (t-1) seasonal period, which was not seen in PILA_G1. ABCO_G3's growth response stayed fairly similar to ABCO_G1 and G2's growth responses, but it also responded positively to precipitation from August-October of the current year-with that seasonal period being the least important predictor of growth. Growth responses to precipitation from CADE_G3 and PILA_G3 seemed to change the most from the 2 smaller diameter groups. CADE_G3 had a stronger lagged response than CADE_G1 and G2 in which it responded positively and strongest to precipitation in the July-September seasonal ( $\mathrm{t}-1)$ period, followed by the October-December seasonal (t-1) period. PILA_G3 had a more lagged response than PILA_G1 in which it responded positively and strongest to precipitation in the November-January (t-1) seasonal period, followed by the July-September (t) seasonal period. This was a different response than what was seen with PILA_G1, having just one month of overlap in January (t). However, growth responses to precipitation for species in diameter group 3 were not as different from diameter group 1 as with the other climate variables - with the exception of the positive response to late summer/early fall precipitation by ABCO_G3 and PILA_G3 which was not exhibited in other diameter groups. A clear trend arose when all diameter groups were combined for each species in which all species generally responded positively to precipitation between early fall (t-1) and early spring (t).

Growth responses to climate moisture index (CMI) followed a similar pattern as growth responses to precipitation (Figure 2.5 B), with some slight differences. Every growth response was also positive, except for a negative response to CMI in the June-August (t-1) seasonal period seen in PILA_G2. ABCO_G1 responded positively and strongest to CMI in the December-February ( $t$ ) seasonal period, followed by the May-July (t) seasonal period, and September-November (t-1) seasonal period. The only predictor variable for CADE_G1 was a 
positive response to CMI in February of the current year. PILA_G1 responded positively and strongest to $\mathrm{CMI}$ in the January-March (t) seasonal period, followed by April-June (t). The only predictor variable for PIPO_G1 was a positive response to CMI in September-November (t-1). Growth responses to CMI were very similar in diameter group 2, with the exception of a negative response seen in PILA_G2 to CMI in the June-August (t-1) seasonal period. Also, ABCO_G2 only responded to CMI in the December-February $(\mathrm{t})$ seasonal period rather than the 3 predictor variables identified for ABCO_G1. ABCO_G3 growth responses to CMI were fairly similar to ABCO_G1 and G2 but with more of a lagged response. ABCO_G3 responded positively and strongest to CMI in November-January (t-1), followed by August-October (t-1). CADE_G3 was noticeably different than CADE_G1 and G2, in which it had a strong lagged response to CMI. The most important predictor variable for growth in response to $\mathrm{CMI}$ from PILA_G3 stayed fairly consistent between the 3 diameter groups. However, the second most important predictor variable for PILA_G3 growth was CMI in the July-September (t) seasonal period. This response was fairly different than what was seen in PILA_G1 and G2, showing that the larger sugar pines were more effected by CMI later in the year. The most important predictor variables for PIPO_G3 were a positive response to CMI in the September-November (t-1) seasonal period, followed by April-June (t-1), and the month of February ( $\mathrm{t}$ ). This was similar to PIPO_G1, but PIPO_G3 had more responses to CMI and also exhibited a lagged response while PIPO_G1 did not.

\subsection{Discussion}

\subsubsection{Growth Responses to Climate Variables}

The general finding that diameter growth decreased due to increasing maximum temperatures in the summer aligned with findings from Yeh and Wensel (2000) as well as Bigelow et al. (2014). This pattern is not surprising since summer is usually the dry period in the Mediterranean climate of the Sierra Nevada range. Therefore, increasing maximum 
temperatures would be expected to intensify drought stress which would subsequently decrease growth. Another notable growth response was the negative response to increasing maximum temperatures in the current summer to early fall from all species in largest diameter group (i.e, \#3), except white fir. One possibility that could lead to this negative response would be increased respiration requirements for larger trees as temperatures increase-as well as the general higher respiration demands that are required as trees age (West 2020). West (2020) also suggested that some of this increase in respiration could be due to increases in maintenance respiration associated with older trees. This distinct difference in growth responses to maximum temperature between the largest and smallest diameter groups was not as apparent with the minimum and mean temperature variables.

One distinct pattern that was observed across all temperature variables was how the largest diameter group had a lagged negative response to temperature. This lagged negative response was to summer temperatures $(t-1)$ for three of the species (ABCO, CADE, and PILA) in diameter group 3 and to March (t-1) temperatures for PIPO_G3; this was observed in every temperature variable except for the lack of influence of maximum temperature on ABCO_G3. Interestingly, Sceicz and MacDonald (1994) found very similar results when comparing growth responses between trees less than 200 years old and greater than 200 years old in which the older trees responded negatively to previous summer temperatures while the younger trees did not. They attributed general differences in growth responses to physiological changes that occur as trees age, such as changes in root, shoot, and cambial growth patterns (Sceicz and MacDonald 1994). Similarly, this response may be due to the inherent nature of larger trees having more tissues for storage, and therefore being influenced more by previous season's growth and growing conditions. Furthermore, increased respiration in larger trees from higher temperatures in the prior year may be decreasing the amount of stored carbohydrates and therefore causing the lagged negative growth response with temperatures. For example, if a tree experienced a stressful growing season the year prior, it may not have as many reserves 
for the flush of growth the following year (Pallardy 2008), especially for a large tree with more growth and metabolic requirements than a smaller tree. Though this current study found a fairly consistent lagged negative response to summer temperatures (t-1), another study done by Bigelow et al. (2014) in the Sierra Nevada, which looked at the same four species that are in the current study, did not find any significant lagged responses to previous summer temperatures. However, though Bigelow et al. (2014) did not capture that lagged response to summer temperatures ( $\mathrm{t}-1)$, they did show a similar finding of a lagged negative response from large ponderosa pine (i.e. similar to PIPO_G3) to spring temperatures in the year prior. This lagged negative response was thought to be attributed to vascular embolisms created by early spring drying events in soil that is frozen or dry due to high vapor pressure deficits created from high temperatures; these vascular embolisms could have subsequently resulted in decreases in rates of carbon fixation (Bigelow et al. 2014). Decreases in carbon fixation during the year prior were thought to have caused a decrease in ring width the following year because the trees may not have had as much stored photosynthate to use for the flush of growth occurring in the spring (Bigelow et al. 2014). However, this is not likely since conifers are fairly resistant to embolisms (Sperry et al. 1994). It is also unclear why large ponderosa pine was the only species to significantly respond negatively to high spring temperatures in the year prior if vascular embolisms are the cause of this lagged response.

Another main finding from the study was that higher adjusted $R^{2}$ values were captured for species in diameter group 3 compared to diameter group 1 -with the exception of a few instances mainly with white fir in which the adjusted $\mathrm{R}^{2}$ slightly decreased from diameter group 1 to group 3. The larger trees also tended to be more influenced at a seasonal scale whereas the smaller trees were influenced mainly by monthly climatic factors-especially for the temperature variables. The inability to explain as much variation in ring width for the smaller, less mature trees could be attributed to more erratic growth since they are usually being influenced by a higher number of environmental factors in the understory such as competition (Chhin et al. 
2008a; Copenheaver and Abrams 2003). In this case, smaller, more suppressed trees may be more influenced by edaphic and/or microclimate gradients (Sprague 2009). This noise (i.e. unwanted growth influences for dendroclimatic analysis) is usually accounted for during analysis in which growth signals are maximized and noise is minimized (Copenheaver and Abrams 2003). However, the higher amount of noise often seen in smaller trees (due to reasons previously mentioned) could be why lower percentages of variation in ring width for smaller trees is explained by the climate variables examined in the current study—even when noise is minimized as much as possible. In other words, this difference is likely because more variation in ring width for smaller trees (versus larger trees) is attributed to other factors not analyzed in this study.

Some general findings were likely due to the inherent nature of the climate in the Sierra Nevada. Especially regarding the dramatic decrease in growth around the year 1977 as seen in Figure 2.2, with a slightly greater decrease in growth perhaps seen for the larger trees. This year (1976 to 1977) is known as one of the worst, if not the worst, drought years in California history (Santos and Godwin 1978). The area of this study was not specifically listed in the report, but it is inferred that the location received less than $60 \%$ of the normal precipitation and just $24 \%$ of normal natural basin runoff-as compared to $43 \%$ natural basin runoff the year prior (Santos and Godwin 1978). Another finding that is likely strongly related to climate is that species mainly responded positively to both precipitation and CMI during late fall-winter. This was generally the case for all species and diameter groups, with slightly more adjusted $\mathrm{R}^{2}$-on average-accounted for in the larger diameter groups. This positive response commonly occurring around this time of year is likely because most yearly precipitation in the northern Sierra Nevada occurs during the winter. One other finding that commonly occurred across all diameter groups and species was the positive response to minimum temperatures in the winter. This was also found to be a significant predictor variable for the same four species studied by Bigelow et al. (2014) in the Sierra Nevada and was speculated to be due to decreases in 
photoinhibition during warmer winters. Photoinhibition is usually referred to as a light-induced decrease in photosynthesis; however, it can also be attributed to high or low temperature extremes (Pallardy 2008). In this case, Bigelow et al. (2014) likely speculated that a decrease in photoinhibition may be the reason for increased growth because recovery of photoinhibition is able to occur at warmer, more moderate temperature levels (Pallardy 2008). However, this is unlikely the reason since limited diameter growth is put on before April in the Sierra Nevada (Fowells 1941). Nonetheless, this finding suggests that trees of all sizes will likely benefit from increasing minimum winter temperatures in the future.

\subsection{Conclusions}

This study underscored how climate variables can have differing growth effects on species based on their size. One of the most interesting findings from the study was the lagged negative response to temperature variables exhibited by the largest diameter group (DBH Group 3) but not so much by the smaller diameter groups. The largest diameter group also tended to respond stronger to temperature variables in general. This can likely be attributed to increased respiration in the more exposed higher canopy leaves (Pallardy 2008) as well as the general increase in respiration demands and root and shoot size as trees age (West 2020). Another interesting finding regarding the largest diameter group, in general, was that more variation in ring width was explained by the climate variables used for dendroclimatic analysis in this study. This could be due to the smaller trees having a higher number of environmental factors that influence their growth in the understory (Chhin et al. 2008a; Copenheaver and Abrams 2003), therefore lowering the percentage of variation that could be explained by temperature, precipitation, and CMI. However, there were also some similarities in terms of growth responses to precipitation and $\mathrm{CMI}$ across all diameter groups which can likely be attributed to the wet season in the Lassen National Forest occurring around the winter months. Another similarity was that species in all diameter groups responded positively to increasing 
winter minimum temperatures, with no distinct difference between diameter groups-

highlighting the benefit that trees of all sizes will likely gain from increasing minimum winter temperatures in the future. 
2.6 Appendix 
Table 2.1 Average basal area and quadratic mean diameter of the four main species studied and for all species combined. The "All" column total for basal area is slightly higher than the sum of the four main species due to small amounts of Jeffrey pine (Pinus jeffreyi) and/or red fir (Abies magnifica) in the sample plots.

\begin{tabular}{lrrrrr}
\hline & ABCO & CADE & PILA & PIPO & ALL \\
\hline BA $\left(m^{2} / \mathrm{ha}\right)$ & 18.11 & 5.48 & 20.47 & 13.87 & 58.27 \\
QMD $(\mathrm{cm})$ & 37.4 & 45.02 & 78.89 & 65.14 & 50.99 \\
\hline
\end{tabular}

Table 2.2 Statistics for the standardized tree ring chronologies for each species and DBH group.

\begin{tabular}{|c|c|c|c|c|c|c|c|c|c|}
\hline Species & $\begin{array}{l}\text { DBH } \\
\text { Group } \\
\#\end{array}$ & $\begin{array}{l}\text { Chronology } \\
\text { Time Span }\end{array}$ & $\begin{array}{l}\text { \# of } \\
\text { Trees }\end{array}$ & $\begin{array}{c}\text { Mean } \\
\text { Sensitivity }\end{array}$ & $\begin{array}{l}\text { Standard } \\
\text { Deviation }\end{array}$ & $\begin{array}{c}\text { Absent } \\
\text { Rings (\%) }\end{array}$ & $\begin{array}{c}\text { Year EPS } \\
\text { Reached } 0.80\end{array}$ & $\begin{array}{c}\text { \# of Trees Needed } \\
\text { to Reach EPS } \\
\text { Value } 0.80\end{array}$ & $\begin{array}{l}\text { Intercore } \\
\text { Correlation }\end{array}$ \\
\hline $\mathrm{ABCO}$ & 1 & $1830-2015$ & 191 & 0.1676 & 0.1714 & 0.0681 & 1885 & 15 & 0.211 \\
\hline CADE & 1 & $1798-2015$ & 40 & 0.1302 & 0.1190 & 0.1308 & 1925 & 15 & 0.221 \\
\hline PILA & 1 & 1876-2015 & 12 & 0.1630 & 0.2568 & 0.3788 & 1957 & 7 & 0.387 \\
\hline PIPO & 1 & $1819-2015$ & 28 & 0.2928 & 0.2579 & 0.4422 & 1969 & 18 & 0.190 \\
\hline $\mathrm{ABCO}$ & 2 & $1851-2015$ & 51 & 0.1949 & 0.3207 & 0.0599 & 1890 & 10 & 0.296 \\
\hline CADE & 2 & $1784-2015$ & 13 & 0.1616 & 0.1496 & 0.3645 & 1893 & 9 & 0.312 \\
\hline PILA & 2 & $1888-2015$ & 7 & 0.1165 & 0.1163 & 0.0000 & 1950 & 6 & 0.411 \\
\hline PIPO & 2 & $1785-2015$ & 9 & 0.1651 & 0.2969 & 0.0623 & $N A^{*}$ & $N A^{*}$ & 0.222 \\
\hline $\mathrm{ABCO}$ & 3 & $1834-2015$ & 15 & 0.1276 & 0.3342 & 0.0000 & 1879 & 9 & 0.319 \\
\hline CADE & 3 & $1812-2015$ & 14 & 0.1608 & 0.3155 & 0.0791 & 1876 & 4 & 0.535 \\
\hline PILA & 3 & $1738-2015$ & 33 & 0.1233 & 0.2086 & 0.2923 & 1856 & 12 & 0.265 \\
\hline PIPO & 3 & $1718-2015$ & 24 & 0.1292 & 0.1687 & 0.1713 & 1799 & 12 & 0.261 \\
\hline
\end{tabular}

${ }^{*}$ NA values noted because EPS did not reach the 0.80 threshold. 


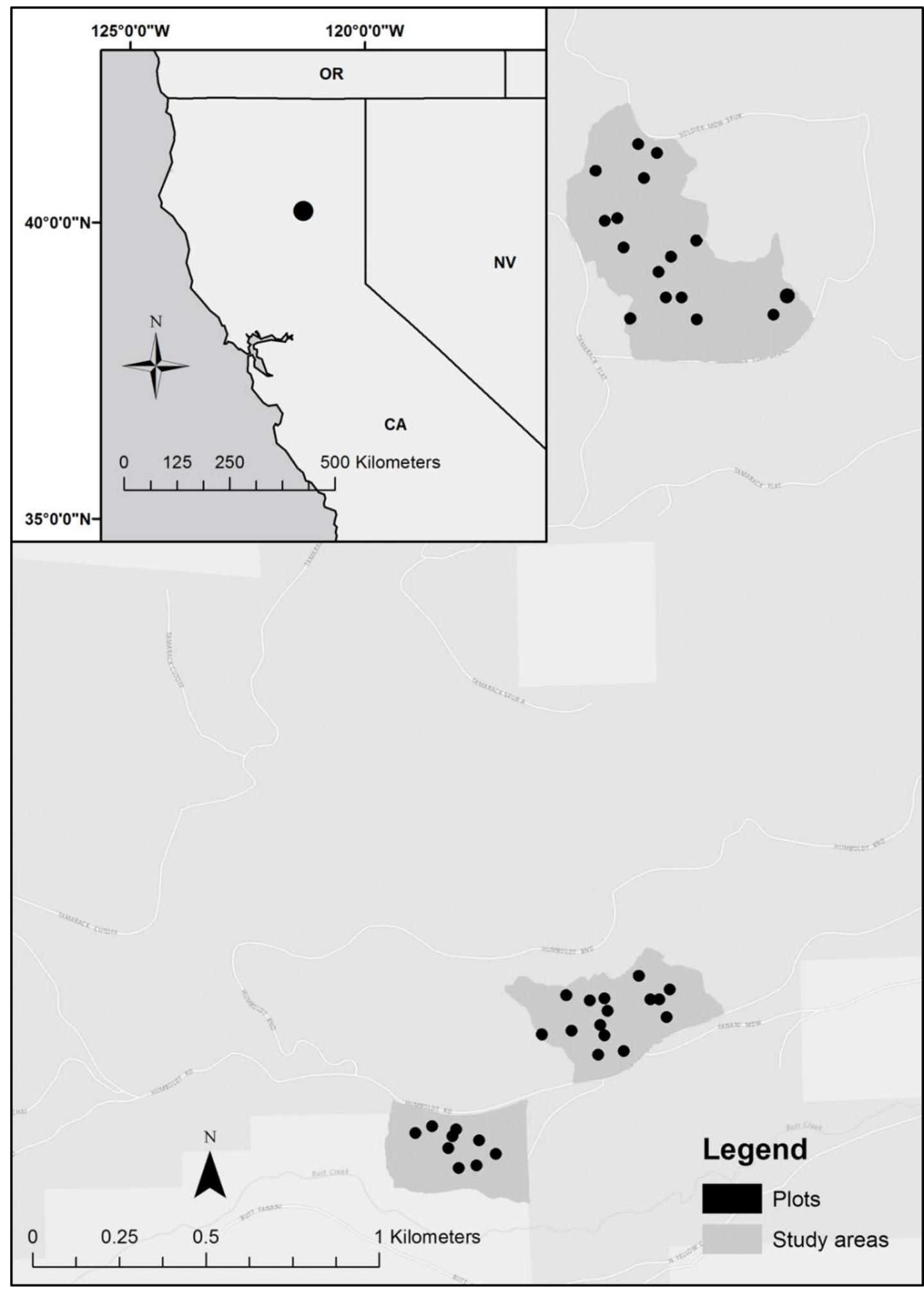

Figure 2.1 Map of study area; located in the southern portion of Lassen National Forest in northern California, southwest of Lake Almanor. Plots are indicated as black dots on the main map. Map courtesy of Johnson et al. (2017). 
A. Species and DBH Group 1 standardized chronologies

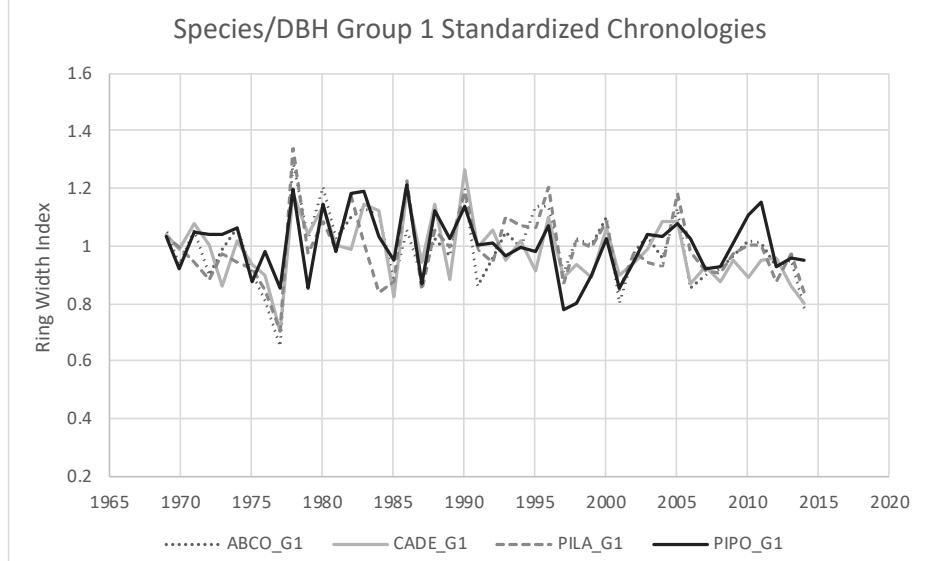

B. Species and DBH Group 2 standardized chronologies

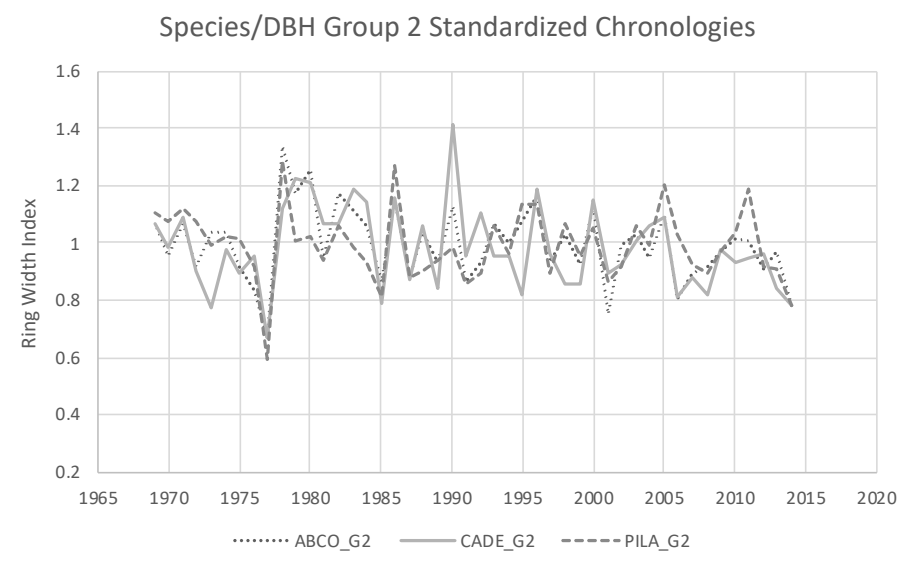

C. Species and DBH Group 3 standardized chronologies

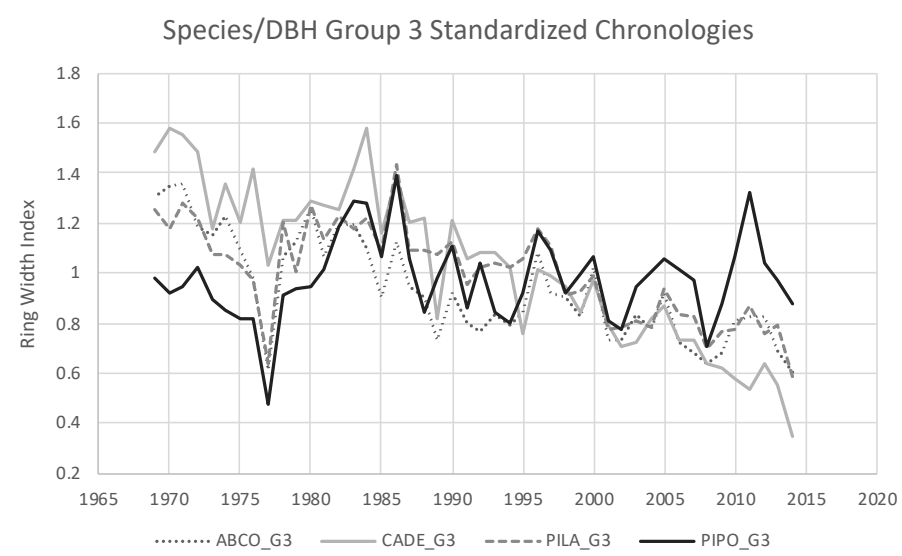

Figure 2.2 Standardized chronologies for the time frame of the dendroclimatological analysis (1969-2014) $. \mathrm{ABCO}=$ Abies concolor, $\mathrm{CADE}=$ Calocedrus decurrens, $\mathrm{PILA}=$ Pinus lambertiana, $\mathrm{PIPO}=$ Pinus ponderosa. $\mathrm{G} 1=$ Diameter Group $1(20.32$ to $\leq 40.64 \mathrm{~cm}$, small size), G2 = Diameter Group 2 (40.64 to $\leq 60.96 \mathrm{~cm}$, medium size), G3 = Diameter Group 3 (> $60.96 \mathrm{~cm}$, large size). PIPO_G2 is not included because its Expressed Population Signal (EPS) value was too low for dendroclimatological analysis. 


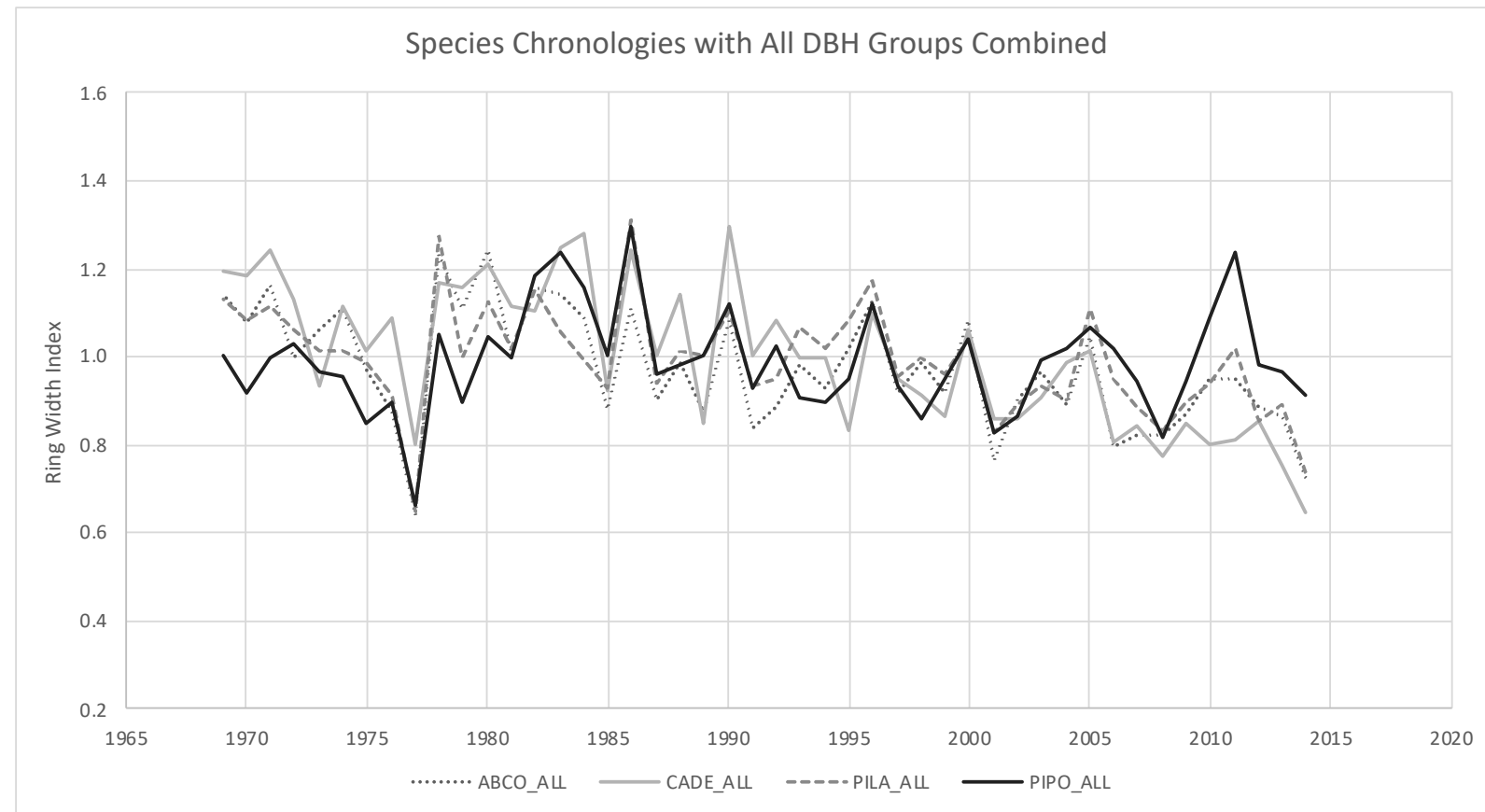

Figure 2.3 Species standardized chronologies with all DBH Groups combined for the time frame of the dendroclimatological analysis (1969-2014). 


\section{A. Maximum Temperature}

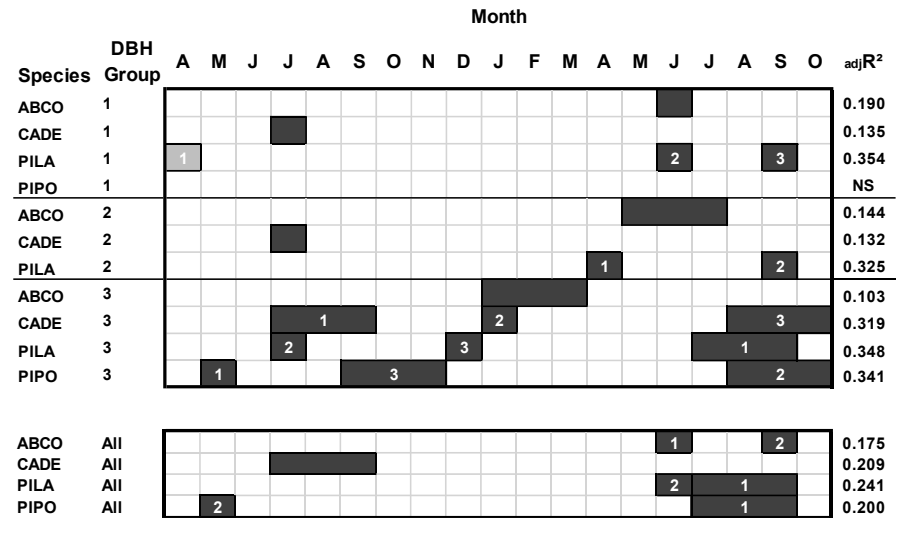

B. Minimum Temperature

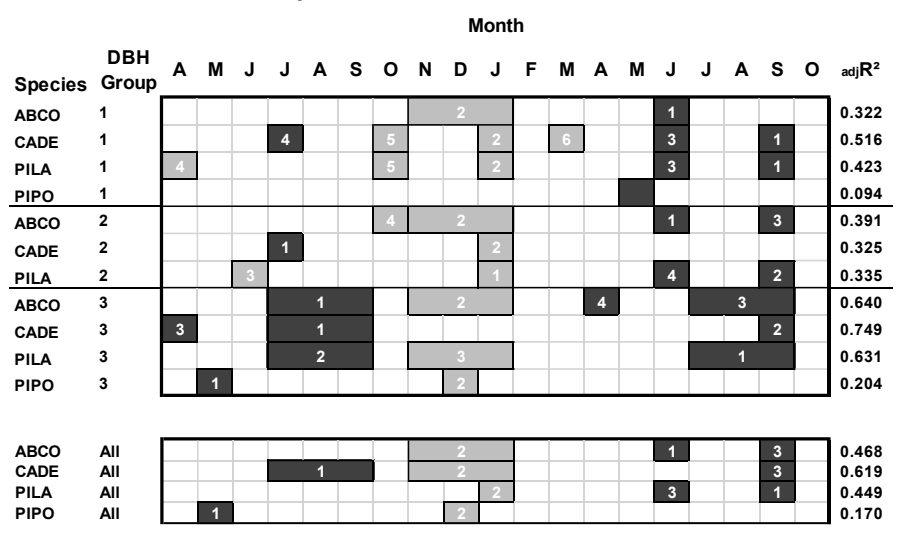

C. Mean Temperature

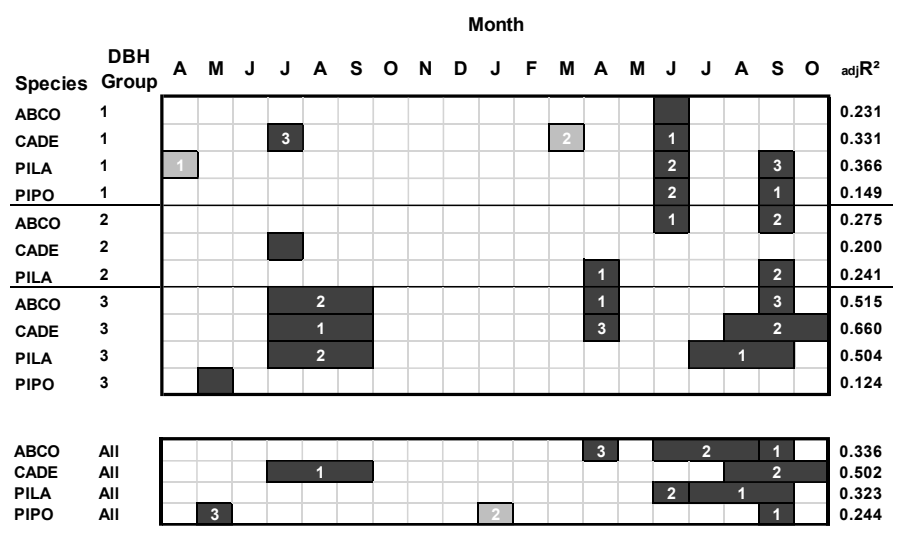

Figure 2.4 Statistically significant $(p<0.05)$ growth responses to maximum temperature, minimum temperature, and mean temperature by species and diameter group and for each species as a whole (i.e., with all diameter groups combined). Darker coloring indicates a negative correlation with growth, while the lighter coloring indicates a positive correlation with growth. Numbers indicate the order of importance for that relationship, with 1 being the most important (according to the standardized partial regression coefficients). Explanatory climate variables expressed either for a monthly period or a 3-month seasonal period. NS = no significant variables in the model. 
A. Precipitation

Month

\begin{tabular}{|c|c|c|c|c|c|c|c|c|c|c|c|c|c|c|c|c|c|c|c|c|c|}
\hline Species & $\begin{array}{l}\text { DBH } \\
\text { Group }\end{array}$ & A & M & $\mathbf{J}$ & $\mathbf{J}$ & A & $\mathbf{S}$ & 0 & $\mathbf{N}$ & D & $\mathbf{J}$ & $F$ & M & A & $\mathbf{M}$ & $\mathbf{J}$ & $\mathbf{J}$ & A & $\mathbf{S}$ & 0 & $\operatorname{adj} R^{2}$ \\
\hline ABCO & 1 & & & & & & & 2 & & & 1 & & & & 3 & & & & & & 0.410 \\
\hline CADE & 1 & & & & & & & & & & & & & & & & & & & & 0.075 \\
\hline PILA & 1 & & & & & & & & & & & 1 & & & 2 & & & & & & 0.281 \\
\hline PIPO & 1 & & & & & & & 1 & & & & & & 2 & & & & & & & 0.205 \\
\hline$A B C O$ & 2 & & & & & & & 2 & & & 1 & & & & & & & & & & 0.326 \\
\hline CADE & 2 & & & & & & & 1 & & & & 2 & & & & & & & & & 0.128 \\
\hline PILA & 2 & & & & 3 & & & & & & 1 & & & & 2 & & & & & & 0.525 \\
\hline$A B C O$ & 3 & & & & & & 2 & & & 1 & & & & & & & & & 3 & & 0.372 \\
\hline CADE & 3 & & & & & 1 & & & 2 & & & & & & & & & & & & 0.258 \\
\hline PILA & 3 & & & & & & & & & 1 & & & & & & & & 2 & & & 0.300 \\
\hline PIPO & 3 & & & & & & & & 2 & & & & 1 & & & & & & & & 0.231 \\
\hline ABCO & All & & & & & & & 2 & & & 1 & & & & & & & & & & 0.432 \\
\hline CADE & All & & & & & & 1 & & & & 2 & & & & & & & & & & 0.211 \\
\hline PILA & All & & & & & & & 2 & & & 1 & & & & & & & & & & 0.371 \\
\hline PIPO & All & & & & & & & 1 & & & & & 2 & & & & & & & & 0.256 \\
\hline
\end{tabular}

B. Climate Moisture Index

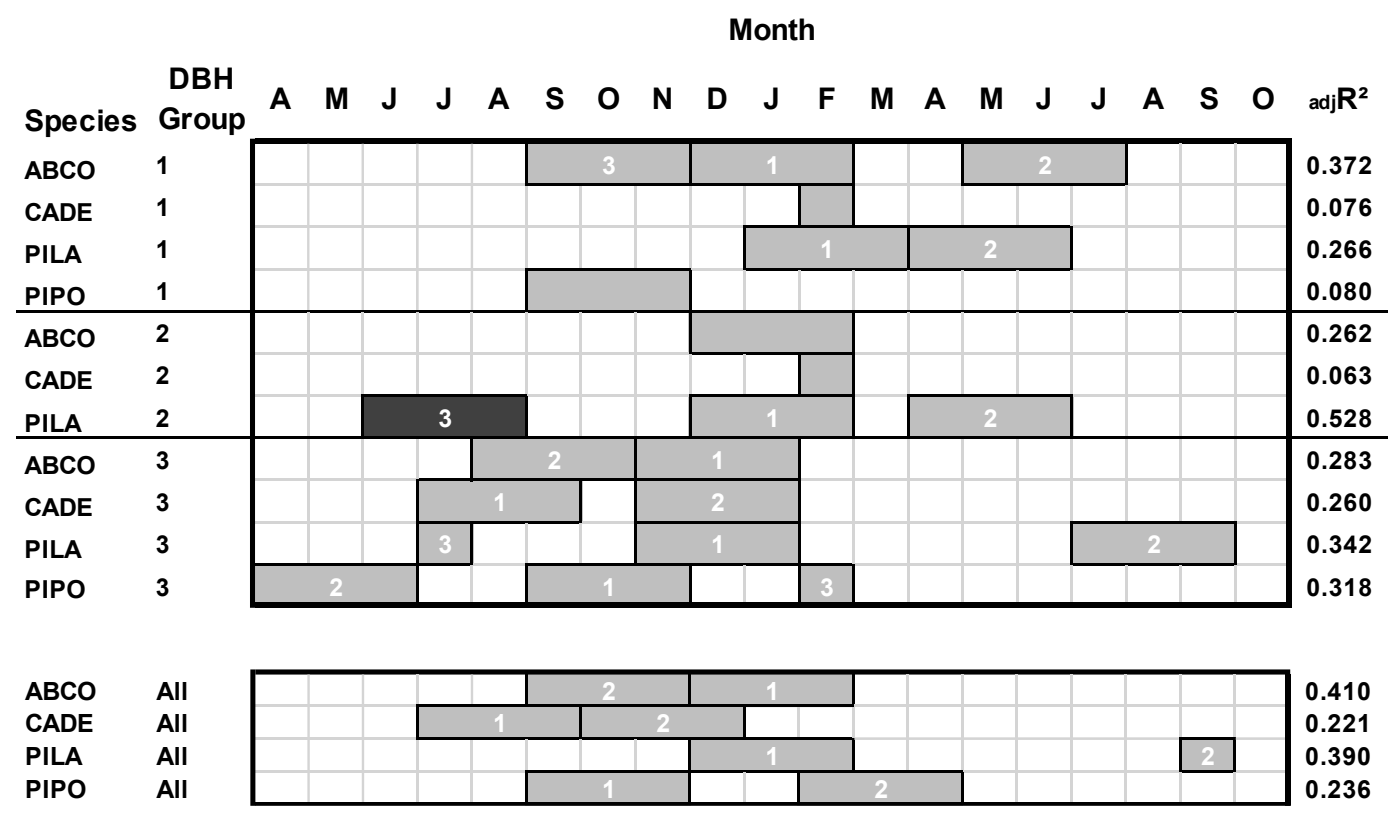

Figure 2.5 Statistically significant $(p<0.05)$ growth responses to precipitation and climate moisture index by species and diameter size group and for each species as a whole (i.e. with all diameter groups combined). Darker coloring indicates a negative correlation with growth, while the lighter coloring indicates a positive correlation with growth. Numbers indicate the order of importance for that relationship, with 1 being the most important (according to the standardized partial regression coefficients). Explanatory climate variables expressed either for a monthly period or a 3-month seasonal period. 
2.7 References 
Akaike, H., 1974. A New Look at the Statistical Model Identification. IEEE Trans. Automat. Contr. 19, 716-723. https://doi.org/10.1109/TAC.1974.1100705

Bailey, R.G., 1994. Ecoregions of the United States. USDA Forest Service. Available online: https://www.fs.usda.gov/rmrs/ecoregions-united-states

Bigelow, S.W., Papaik, M.J., Caum, C., North, M.P., 2014. Faster growth in warmer winters for large trees in a Mediterranean-climate ecosystem. Clim. Change 123, 215-224. https://doi.org/10.1007/s10584-014-1060-0

Briffa, K. R., and P. D. Jones, 1990. Basic chronology statistics and assessment. In Methods of Dendrochronology. Applications in the Environmental Sciences, edited by E. R. Cook and L. A. Kairiukstis, pp. 137-152. Kluwer Academic, Dordrecht.

Castaldi, C., Marchi, M., Vacchiano, G., Corona, P., 2020. Douglas-fir climate sensitivity at two contrasting sites along the southern limit of the European planting range. J. For. Res. 31, 2193-2204. https://doi.org/10.1007/s11676-019-01041-5

Chhin, S., Hogg, E.H. (Ted., Lieffers, V.J., Huang, S., 2008b. Potential effects of climate change on the growth of lodgepole pine across diameter size classes and ecological regions. For. Ecol. Manage. 256, 1692-1703. https://doi.org/10.1016/j.foreco.2008.02.046

Chhin, S., Wang, G.G., 2008a. Climatic response of Picea glauca seedlings in a forest-prairie ecotone of western Canada. Ann. For. Sci. 65, 1-8. https://doi.org/10.1051/forest:2007090

Cook, E.R., 1985. A Time Series Analysis Approach to Tree Ring Standardization PhD Thesis. University of Arizona.

Copenheaver, C.A., Abrams, M.D., 2003. Dendroecology in young stands: Case studies from jack pine in northern lower Michigan. For. Ecol. Manage. 182, 247-257. https://doi.org/10.1016/S0378-1127(03)00049-5

Daly, C., Halbleib, M., Smith, J.I., Gibson, W.P., Doggett, M.K., Taylor, G.H., Curtis, J., Pasteris, P.P., 2008. Physiographically sensitive mapping of climatological temperature and precipitation across the conterminous United States. Int. J. Climatol. 28, 2031-2064.

Habeck, R. J. 1992. Pinus lambertiana. In: Fire Effects Information System, [Online]. U.S. Department of Agriculture, Forest Service, Rocky Mountain Research Station, Fire Sciences Laboratory (Producer). Available: https://www.fs.fed.us/database/feis/plants/tree/pinlam/all.html [2019, December 112019, December 11].

Hogg, E.H., 1997. Temporal scaling of moisture and the forest-grassland boundary in western Canada. Agric. For. Meteorol. 84, 115-122. https://doi.org/10.1016/S0168-1923(96)023805

Holmes, R.L., 1983. Computer-assisted quality control in tree-ring dating and measurement. Tree-ring Bull. 43, 69-78. 
IPCC, 2013: Climate Change 2013: The Physical Science Basis. Contribution of Working Group I to the Fifth Assessment Report of the Intergovernmental Panel on Climate Change [Stocker, T.F., D. Qin, G.-K. Plattner, M. Tignor, S.K. Allen, J. Boschung, A. Nauels, Y. Xia, V. Bex and P.M. Midgley (eds.)]. Cambridge University Press, Cambridge, United Kingdom and New York, NY, USA, 1535 pp.

Johnson, C., Chhin, S., Zhang, J., 2017. Effects of climate on competitive dynamics in mixed conifer forests of the Sierra Nevada. For. Ecol. Manage. 394, 1-12. https://doi.org/10.1016/j.foreco.2017.03.017

Kosiba, A.M., P.G. Schaberg, S.A. Rayback, and G.J. Hawley. 2017. Comparative growth trends of five northern hardwood and montane tree species reveal divergent trajectories and response to climate. Canadian Journal of Forest Resources. 47: 743-754.

Luers, A.L., Cayan, D.R., Franco, G., Hanemann, M., Croes, B., 1990. Our changing climate. Agric. For. Meteorol. 50, 55-64. https://doi.org/10.1016/0168-1923(90)90138-V

Martínez-Ferri, E., Manrique, E., Valladares, F., Balaguer, L., 2004. Winter photoinhibition in the field involves different processes in four co-occurring Mediterranean tree species. Tree Physiol. 24, 981-990. https://doi.org/10.1093/treephys/24.9.981

Mérian, P., Lebourgeois, F., 2011. Size-mediated climate-growth relationships in temperate forests: A multi-species analysis. For. Ecol. Manage. 261, 1382-1391. https://doi.org/10.1016/j.foreco.2011.01.019

Nippert, J.B., Duursma, R.A., Marshall, J.D., 2004. Seasonal variation in photosynthetic capacity of montane conifers. Funct. Ecol. 18, 876-886. https://doi.org/10.1111/j.02698463.2004.00909.x

Oliver, W. W. and Ryker, R.A., 2014. Pinus ponderosa Dougl. ex Laws. Agric. Handb. 654 1-19. https://doi.org/10.5962/bhl.title.84691

Pallardy, S.G., 2008. Physiology of Woody Plants, 3rd Editio. ed. Elsevier Inc.

PRISM Climate Group, Oregon State University, http://prism.oregonstate.edu, created 20 Nov 2018.

Santos, J.T., Godwin, A.F., 1978. The 1976-1977 California Drought - A Review.

Speer, J.H., 2010. Fundamentals of Tree-Ring Research. University of Arizona Press, Tucson, AZ.

Sperry, J.S., Nichols, K.L., Sullivan, J. E. M., Eastlack, S.E., 1994. Xylem Embolism in RingPorous, Diffuse-Porous, and Coniferous Trees of Northern Utah and Interior Alaska. Ecology. 75, 1736-1752.

Sprague, A., 2009. Evaluating the effect of climate in a Sierran Mixed Conifer forest. Berkeley Sci. J. 13, 44-53. 
Szeicz, J.M., MacDonald, G.M., 1994. Age-dependent tree-ring growth responses of subarctic white spruce to climate. Can. J. For. Res. 24, 120-132. https://doi.org/10.1139/x94-017

Tollefson, Jennifer E. 2008. Calocedrus decurrens. In: Fire Effects Information System, [Online]. U.S. Department of Agriculture, Forest Service, Rocky Mountain Research Station, Fire Sciences Laboratory (Producer). Available: https://www.fs.fed.us /database/feis/plants/tree/caldec/all.html [2019, December 112019, December 11].

USDA Forest Service, 1999. M261 Sierran Steppe-Mixed Forest-Coniferous Forest-Alpine Meadow Province. Available online:

https://www.fs.fed.us/land/ecosysmgmt/colorimagemap/images/m261.html

Vieira, J., Campelo, F., Nabais, C., 2009. Age-dependent responses of tree-ring growth and intra-annual density fluctuations of Pinus pinaster to Mediterranean climate. Trees - Struct. Funct. 23, 257-265. https://doi.org/10.1007/s00468-008-0273-0

Way, D.A., Oren, R., 2010. Differential responses to changes in growth temperature between trees from different functional groups and biomes: a review and synthesis of data. Tree Physiol. 30, 669-688. https://doi.org/10.1093/treephys/tpq015

West, P.W., 2020. Do increasing respiratory costs explain the decline with age of forest growth rate? J. For. Res. 31, 693-712. https://doi.org/10.1007/s11676-019-01020-w

Yamaguchi, D.K., 1991. A simple method for cross-dating increment cores from living trees. Can. J. For. Res. 21, 414-416.

Yeh, H.Y., Wensel, L.C., 2000. The relationship between tree diameter growth and climate for coniferous species in northern California. Can. J. For. Res. 30, 1463-1471. https://doi.org/10.1139/x00-074

Zar, J.H., 1999. Biostatistical Analysis. Prentice Hall, Upper Saddle River.

Zouhar, Kris. 2001. Abies concolor. In: Fire Effects Information System, [Online]. U.S. Department of Agriculture, Forest Service, Rocky Mountain Research Station, Fire Sciences Laboratory (Producer). Available:

https://www.fs.fed.us/database/feis/plants/tree/abicon/all.html [2019, December 112019, December 11]. 


\section{Chapter 3: Daily and stem cycle analysis of Pinus ponderosa and Pinus lambertiana: Radial release effects and climatic drivers of stem radial fluctuations}

\subsection{Introduction}

The forests of the Sierra Nevada region of California are facing multiple threats due to climate change issues such as increasing temperatures and earlier melting of snowpack (IPCC 2013, Luers et al. 1990), as well as issues due to the impacts of previous fire suppression and inappropriate logging. The Sierra Nevada region is known for its warm, dry summers and cool, moist winters with most precipitation occurring in the winter (between October and March). During these already dry growing seasons, increased stem densities have likely intensified tree stress and competition (Fecko et al. 2008). Management of stem densities via thinning treatments is a common mitigation technique to limit competition and moisture stress of the retained trees (Fecko et al. 2008). Since large, old growth trees provide multiple ecosystem benefits such as wildlife habitat, carbon sequestration, and structural diversity, new thinning treatments designed to thin a certain radius around these trees are being implemented in an attempt to improve vigor and reduce mortality of these legacy trees. Hood et al. (2018) found that, for legacy Pinus ponderosa (ponderosa pine) and Pinus jeffreyi (Jeffrey pine), radial thinning treatments that removed every tree less than $25.4 \mathrm{~cm}$ dbh within the width of the legacy tree crowns were not sufficient to cause an increase in basal area increment (BAI). They suggested that a larger radius of thinning may increase legacy tree BAI more. However, there are other benefits to these thinning treatments in general than just increased growth. Thinning treatments may limit drought induced mortality (Bradford and Bell 2017), lower wildfire risk due to the creation of heterogeneous canopy conditions (Hood et al. 2018; Fulé et al. 2012), and lower the likelihood of bark beetle attacks. These larger trees with improved growing conditions would experience less stress and likely make them less susceptible to bark beetle attackssince bark beetles usually target weak/stressed trees (Bentz et al. 2010; Fettig et al. 2007). Though current methods attempting to improve vigor of large trees (often referred to as legacy 
trees) involve thinning to a certain radius around them (i.e. Hood et al. 2018), there is little information on the specific radius and their effectiveness in the Sierra Nevada region.

The use of dendrometers to measure tree stem fluctuations —often in sub-hourly intervals - can provide useful short-term results of thinning treatments such as tree water status and radial growth (Viera et al. 2013). In addition, comparing sub-hourly tree stem measurements with multiple climate variables can provide key insights as to what climate variables are driving stem fluctuations throughout the day. This can help to highlight which variables managers can alter via thinning treatments to improve growth and vigor. Most studies which use dendrometer readings to assess stem fluctuations use methods of analysis that either summarize the readings using a daily approach (i.e. daily amplitude, mean, minimum, and maximum values) (Duchesne and Houle 2011) or using a stem cycle approach (Viera et al. 2013; Ziaco and Biondi 2018; Deslauriers et al. 2003). The stem cycle approach breaks down the dendrometer readings into contraction, expansion, and stem-radius increment and can analyze cycles that last longer than a day (van der Maaten et al. 2016). Contraction occurs as the stem variation goes below the previous maximum, expansion occurs as the stem goes above the previous minimum, and stem-radius increment occurs when the stem expands further than the previous maximum (e.g., Figure 3.2B). A study in the Sierra Nevada which looked at the effect of thinning and prescribed burns on water storage in Jeffrey pine via band dendrometers found that thinning treatments caused the stems of the trees left behind to contract more on a daily basis_especially during the latter (and drier) part of the growing season (Fecko et al. 2008). They attributed this to the trees in the thinned treatments having more available water to recharge their stems with during that part of the year, therefore causing their stems to contract more throughout the day since they could then use that larger amount of recharged water for their transpiration needs (Fecko et al. 2008). A study done by Viera et al. (2013) on maritime pine (Pinus pinaster) in the Mediterranean climate region of the west coast 
of Portugal found that daily variations in stem radius were mainly controlled by transpiration and therefore stem fluctuations were most influenced by temperature and tree water status.

Many studies have been done to assess drivers of daily stem fluctuations; however, there are limited studies in the Sierra Nevada region (Fecko et al. 2008). Similarly, there have been no studies looking at the effects of radial thinning treatments on daily stem fluctuations of the retained large/legacy trees within the Sierra Nevada region. One objective of this current study is to analyze sub-hourly stem fluctuations of ponderosa and sugar pines in multiple different radius thinning treatments to assess the short-term effects of these treatments. This will help to provide guidance earlier to managers as to what thinning radius, whether it be diameter-based or a fixed radius, improves tree health and vigor of the remaining legacy trees. The other objective of this study is to analyze the sub-hourly dendrometer data collected on the ponderosa and sugar pines within those varying radial thinning treatments to assess climatic drivers of hourly stem fluctuations.

\subsection{Methods}

\subsubsection{Study Site}

The study took place in the Lassen National Forest in the northern Sierra Nevada range of California at an average elevation of $1530 \mathrm{~m}$ (Figure 3.1). The ecoregion of the Lassen National Forest is categorized as the M261 Sierran Steppe-Mixed Forest-Coniferous Forest-Alpine Meadow Province (Bailey 1994). The northern Sierra Nevada region in general is described as having warm, dry summers and cool, moist winters with most of the yearly precipitation generally happening in the winter (between October and March). Furthermore, most precipitation at higher elevations in the winter comes in the form of snow and is usually an important resource for moisture during the growing season as the snow melts (Yeh and Wensel 2000). The main soils found in this region are ultisols on mountain slopes with humid air, dry 
alfisols at lower elevations, and entisols in the narrow floodplains and alluvial parts of the valley (USDA Forest Service 1999).

\subsubsection{Site Selection \& Field Methods}

The study sites were selected based on criteria that includes containing an old-growth pine which was defined as having a breast height diameter of at least $63.5 \mathrm{~cm}$. These oldgrowth pines were designated as the plot centers in which radial thinning treatments were then applied around them removing all mid and understory trees except healthy pines greater than $40.6 \mathrm{~cm}$ in diameter. A total of 16 plots were selected for this study; 11 of those plots had an old-growth sugar pine as the plot center and 5 plots had an old-growth ponderosa pine as the plot center.

Treatment types for sugar pine consisted of:

1) 3 control plots with no thinning (referred to as Con)

2) 3 plots with a thinning radius of $9.1 \mathrm{~m}$ around the focal tree with zero competitors left within the radius (referred to as $\mathrm{R} 30 \mathrm{C} 0$ ) (this is the common radial thinning radius in the Lassen National Forest (John Zarlengo, USDA Forest Service, personal communication))

3) 2 plots with a thinning radius of $9.1 \mathrm{~m}$ keeping two competitors within the radius (R30C2)

4) 3 plots with a radius based on the old-growth pine diameter multiplied by $1 \mathrm{ft} / \mathrm{in}$ of $\mathrm{DBH}$ and then multiplied by 1.25 which ranged from $14.0-18.0 \mathrm{~m}$ (RD1.2)

To further summarize, dendrometer units were attached to three sugar pines in the control treatment group with an average dbh $81.8 \mathrm{~cm}$, three sugar pines in the R30C0 treatment group with an average dbh of $88.1 \mathrm{~cm}$, two sugar pines in the $\mathrm{R} 30 \mathrm{C} 2$ treatment group with an average 
dbh of $99.1 \mathrm{~cm}$, and three sugar pines in the RD1.2 treatment group with an average dbh of $111.3 \mathrm{~cm}$ (Table 3.1 and 3.2).

Treatment types for ponderosa pine consisted of:

1) 2 control plots with no thinning (Con)

2) 3 plots with a thinning radius of the diameter multiplied by $1 \mathrm{ft} / \mathrm{in}$ of $\mathrm{DBH}$ and then multiplied by 1.25 which ranged from $11.3-14.0$ m (RD1.2)

Dendrometer units were attached to two ponderosa pines in the control treatment with an average dbh of $89.4 \mathrm{~cm}$ and three in the RD1.2 treatment group with an average $\mathrm{dbh}$ of $87.6 \mathrm{~cm}$ (Table 3.1 and 3.2). All radial thinning treatments mentioned above were applied approximately one and a half years before dendrometer measurements were taken for this study.

Automatic point dendrometers were made using methods from Wang and Sammis (2008). Dendrometers were then connected to the trees by scraping off some of the outer bark to have a clean surface for the dendrometer to mount to. Care was taken to avoid exposure of cambium layer (not all bark was removed). Using two C-clamps with predrilled holes for mounting them to the tree, two $7.6 \mathrm{~cm}$ screws were drilled into the tree and mounted to the $\mathrm{C}$ clamps using nuts on both sides of the clamp. Then the point dendrometer was placed in the Cclamp making sure the sensor's resistor slider (plunger) was pushed in to a depth of approximately $3 \mathrm{~mm}$. The dendrometer was then connected to an Onset HOBO datalogger. A field laptop was connected to the data logger to launch the unit, setting a measurement time interval of 15-minutes. Data from the data loggers were then recorded every few weeks to secure the previously logged measurements to avoid any potential data loss. Other climate data were downloaded from the Chester, CA RAWs weather station (https://raws.dri.edu/cgibin/rawMAIN.pl?caCCHS). This included hourly measurements of mean air temperature, mean 
relative humidity, total solar radiation, and total precipitation (Figure 3.3). HOBO data and Chester RAWs weather station data were then combined for analysis purposes.

\subsubsection{Analysis Methods \\ Combining and Running Data Through DendrometeR}

As for the HOBO data, the dendrometer unit recorded data in voltages rather than actual units. To convert the voltages from the dendrometer unit, a regression equation was made by manually pushing in the sensor's plunger at $0.2 \mathrm{~mm}$ increments and recording the respective voltage at each increment. Using this regression equation, I was able to convert the voltage readings to millimeter readings.

The respective HOBO data for each tree was compiled and converted to actual units. Any gaps in measurements due to technical issues were filled in with "NA" so that the data could be run through the dendrometeR R package (van der Maaten et al. 2016)—since this is required in order for the package to run properly. Once initial compiling and cleaning of the data was finished, outliers were located by calculating Z-scores for each dendrometer measurement using the respective daily mean and daily standard deviation associated with that measurement. If Z-scores for a given sub-hourly dendrometer measurement were $\geq 2$ or $\leq-2$, "NA" values were substituted (Ziaco and Biondi 2018). This was done to account for outlier measurements in the dendrometer data due to technical issues that may have occurred with the dendrometer units or the data loggers themselves_or even from wildlife (i.e. squirrels) standing on the dendrometer set-up. After this step was finished, the data was then ready to run through the dendrometeR $R$ package made by van der Maaten et al. (2016). This package was used to generate output for both the stem cycle and daily approaches.

The raw dendrometer data with all "NA" values added in as previously mentioned was then used as input for the dendrometeR package (van der Maaten et al. 2016). This data file 
had three columns: "TIMESTAMP" (in 15-minute intervals), "mmGROWTH" (mm), and "SOILMSTR" (\%). Some reformatting was done within $\mathrm{R}$ to assure the raw data was in proper format for the dendrometeR package. Code for this reformatting was adapted from the dendrometeR package manual (van der Maaten et al. 2016). Any "NA" values in the dendrometer data were gap filled using the "fill_gaps" function with the smoothing parameter $(\mathrm{Hz})$ set to the default value of 0.01 (no smoothing) used by van der Maaten et al. (2016) to ensure gaps were estimated primarily by data adjacent to the gaps. Once gaps were filled, hourly averages of the dendrometer data were calculated. Then this data was combined with the Chester, CA RAWS station data which was also in hourly increments (https://raws.dri.edu/cgi-bin/rawMAIN.pl?caCCHS). Both datasets were assured to be in Pacific Daylight Time (PDT) before combining since measurements were taken in the Spring/Summer. Hourly averages of the dendrometer data were calculated because the temporal resolution of the environmental data needs to be the same or higher than the dendrometer data for the dendrometeR package to work (van der Maaten et al. 2016).

Once hourly averages of the gap-filled HOBO data were combined with the Chester RAWs station data for each focal tree, the datasets needed to be combined by speciestreatment group so that I could assess the treatment effects and climatic drivers of stem variation across each given species-treatment group. To do this, I first standardized the dendrometer data sets for each focal tree using a locally weighted quadratic regression via the "loess" function in the program R, similar to Chhin et al. (2010). Once the dendrometer datasets were standardized, the initial residuals were averaged across the whole species-treatment group for each hourly increment, then cumulative values were calculated at each successive hour. These cumulative standardized dendrometer measurements will be further referred to as normalized stem variation. After the normalized stem variation was calculated, I could then run 
the dendrometeR package the rest of the way through to get the daily and stem cycle statistics for each species-treatment group.

Now that everything was combined for each respective species-treatment group, the three distinct stem cycle phases (contraction, expansion, stem radial increment) were identified using the "phase_def" function with the default parameter values as used in van der Maaten et al. (2016). This function first looks within a specified daily time window, and then offsets the original dendrometer series to make sure the initial extrema identified are the actual extrema of each cyclic phase (van der Maaten et al. 2016). The output from the "phase_def" function was used as input for the "cycle_stats" function in which cycles were defined based on the previously identified phases. A full stem cycle is denoted by a contraction, expansion, and a stem radial increment phase (if any increment occurs). For example, a cycle could consist of just the contraction and expansion phases if no stem radial increment occurs. Statistics such as magnitude (of normalized radial change), duration, and timing for each phase and cycle were then calculated (van der Maaten et al. 2016). The smoothing parameter for the "cycle_stats" function was set to the default value of 4 used by Deslauriers et al. (2011) whom this function was derived from. This value of the smoothing parameter is useful for handling data with moderate levels of noise. The "climate_seg" function was then used to calculate the mean, min, max, and sum of all the environmental parameters for each given stem cyclic phase and cycle. The main stem cycle statistics from the dendrometeR package consisted of magnitude and duration of each stem cyclic phase as well as the mean and sum of the environmental variables during that respective phase (sum is only applicable to precipitation data).

Daily statistics were also calculated for the environmental and normalized stem variation data. The "daily_stats" function was used to calculate these daily statistics using a smoothing parameter value of 1 . A smoothing parameter of 1 represents no smoothing and is the default parameter used by van der Maaten et al. (2016) for this function to ensure that daily statistics 
were not influenced by the day prior or after. Daily statistics from the dendrometeR package consisted of amplitude of normalized radial change, timing of min and max of the normalized stem variation data, as well as mean and sum of each environmental variable (sum only applicable to precipitation data).

\section{Analyzing Output from the DendrometeR Package}

To analyze dendrometeR package output for the stem cycle approach, Pearson correlations were run to determine the association between each climate variable and the magnitude and the durations of standardized stem fluctuations for each cyclic phase. In addition, a correlation matrix was developed on growth parameters (magnitude and duration) to assess if there was any correlation between magnitude and duration for all combinations of phases for a total of 15 separate Pearson correlations (i.e. magnitude of phase 1 vs duration of phase 1 , magnitude of phase 1 vs magnitude of phase 2 , etc.). To improve robustness of my results, variables were considered significantly correlated if after 1,000 bootstrapped correlations (random seed of 12345) the $95 \%$ confidence interval of their correlation coefficient did not include zero, similar to Viera et al. (2013). Correlations and bootstraps were done separately for each climate variable versus phase duration, for each climate variable versus phase magnitude, and for each pair of variables in the correlation matrix. For the daily approach, Pearson correlations were run to determine the association of each individual climate variable with amplitude of daily standardized radial variation. As with the analysis of the stem cycle approach, I improved the robustness of my results by running 1,000 bootstrapped correlations with a random seed of 12345 . Variables were considered significantly correlated if after 1,000 bootstrapped correlations the $95 \%$ confidence interval of their correlation coefficient did not include zero, similar to Viera et al. (2013). 


\subsection{Results}

\subsubsection{Climate Data}

The overall mean hourly solar radiation recorded from May $27^{\text {th }}$ to August $25^{\text {th }}, 2016$ was $0.32^{\circ} \mathrm{KW}-\mathrm{hr} / \mathrm{m}^{2}$ with a standard deviation of $0.36^{\circ} \mathrm{KW}-\mathrm{hr} / \mathrm{m}^{2}$ (Figure $\left.3.3 \mathrm{~A}\right)$. Mean air temperature was $18.55^{\circ} \mathrm{C}$ with a standard deviation of $8.54^{\circ} \mathrm{C}$ (Figure 3.3B). The mean relative humidity for that time span of the measurement period was $42.40 \%$ with a standard deviation of $22.79 \%$ (Figure $3.3 \mathrm{C}$ ). The mean hourly precipitation was $0.01 \mathrm{~mm}$ with a standard deviation of $0.13 \mathrm{~mm}$ (Figure 3.3D). The total amount of precipitation for those three months was $18.02 \mathrm{~mm}$. To further highlight the lack of precipitation, there were only two days - for a total of 14 hours combined - that precipitation was recorded at the Chester RAWs station during those three months.

\subsubsection{Growth Variable Correlations}

One of the most common significant correlations for the sugar pine groups was the positive correlation between magnitude and duration of the same phase (Table 3.3). For example, as magnitude of contraction increases, so would the duration of contraction. This significant positive correlation between magnitude of contraction and duration of contraction was seen in PILA_RD1.2. The most common occurrence of this relationship was the positive correlation between magnitude of expansion and duration of expansion, and this positive correlation was observed in both the PILA_Con, and PILA_R30C0 treatment groups. There was also a very strong positive correlation between magnitude of radial increment and duration of radial increment for PILA_R30C0 and PILA_RD1.2. The other positive correlation found between growth variables was the positive correlation between magnitude of expansion and magnitude of contraction seen in PILA_RD1.2. Two negative correlations were found, with the strongest negative correlation being between duration of stem-radius increment and magnitude of contraction for the PILA_R30C2 treatment group. 
The most common significant correlation for the ponderosa pine groups was the positive correlation between magnitude of expansion and magnitude of contraction seen in PIPO_Con and PIPO_RD1.2 (Table 3.3). There was also a significant negative correlation between magnitude of expansion and duration of contraction for PIPO_Con. This was the only significant correlation found in the ponderosa pine group that was not found in the sugar pine group. Lastly, a significant positive correlation was found between magnitude of expansion and duration of expansion for the PIPO_Con treatment group.

\subsubsection{Daily Approach}

The most common and strongest significant correlations for the sugar pine treatment groups were seen between daily amplitude and daily mean solar radiation for PILA_R30C0 and PILA_R30C2 (Table 3.4). Only one significant positive correlation was found between daily amplitude and mean relative humidity, occurring in the PILA_RD1.2 treatment group. No significant correlations were found between amplitude and daily sum of precipitation.

The most common significant correlation for the ponderosa pine treatment groups was the positive correlation between daily amplitude and mean relative humidity for both the PIPO_Con and PIPO_RD1.2 treatment groups. The only significant negative correlation found in the ponderosa pine groups was the negative correlation between amplitude of daily stem variation and daily mean air temperature for the RD1.2_PIPO treatment group. As with the sugar pine treatment groups, there were no significant correlations found between amplitude and daily sum of precipitation for the ponderosa pine treatment groups.

\subsubsection{Stem Cycle Approach}

In general, the stem variation of the sugar pine treatment groups were most often correlated to mean solar radiation, mean air temperature, and mean relative humidity (Table 
3.5). The most common occurrences of negative correlations were with mean solar radiation and mean air temperature. Furthermore, the sugar pine groups that had the radial thinning treatments applied to them were more often correlated to the environment variables than the control treatment groups were. The duration of contraction for both the PILA_R30C2 and PILA_RD1.2 treatment groups was negatively correlated with mean solar radiation. The duration of contraction for both the PILA_R30C0 and PILA_RD1.2 treatment groups was negatively correlated with mean air temperature and positively correlated with mean relative humidity. The magnitude of contraction followed a similar pattern for PILA_RD1.2 in which the magnitude of contraction was negatively correlated with mean solar radiation and mean air temperature but positively correlated with mean relative humidity.

One notable finding for the sugar pine group for the expansion phase correlations was that the duration of expansion was positively correlated with mean air temperature and negatively correlated with mean relative humidity for PILA_RD1.2. The duration of expansion for PILA_R30C2 was positively correlated to mean solar radiation. All correlations between magnitude of expansion and the environmental variables for the sugar pine group were positive. There were also fairly strong significant positive correlations between magnitude of expansion and mean solar radiation for both the PILA_R30C2 and PILA_RD1.2 treatment groups. The only other correlation found with the magnitude of expansion was the significant positive correlation with magnitude of expansion and mean air temperature for the PILA_RD1.2 treatment group.

There was a very similar pattern between the significant correlations found for the duration of stem radial increment and the magnitude of stem radial increment for the sugar pine treatment groups. Most of these correlations were found for the R30C2_PILA treatment group. In this case, the duration of radial increment and the magnitude of radial increment were both negatively correlated to mean solar radiation and mean air temperature but positively correlated to mean relative humidity. Both duration and magnitude of stem radial increment had fairly 
strong mean correlation values for those significant correlations mentioned. The other significant correlation found for the radial increment phase was the positive correlation between magnitude of radial increment and mean solar radiation for the PILA_RD1.2 group.

For the ponderosa pine group and for correlations with the contraction phase, both the PIPO_Con and PIPO_RD1.2 treatment groups had the same correlations with duration of contraction. In this case, they both were significantly negatively correlated to mean solar radiation and mean air temperature and positively correlated to mean relative humidity. Interestingly, the magnitude of contraction was positively correlated with mean solar radiation and air temperature for PIPO_Con, whereas the duration of contraction was negatively correlated with those same variables for the PIPO_Con treatment group. Lastly, the magnitude of contraction for PIPO_RD1.2 was positively correlated to mean relative humidity.

There were not many significant correlations identified for the ponderosa pine groups for the expansion phase. In this case, the PIPO_Con treatment group had a positive correlation between duration of expansion and both mean solar radiation and mean air temperature. The only other significant correlation was also with the PIPO_Con treatment group. In this case, there was a negative correlation between duration of expansion and mean relative humidity for the PIPO_Con treatment group. There were no significant correlations found between the magnitude of expansion and the environmental variables for the ponderosa pine groups. In addition, there were limited significant correlations found between the stem radial increment phase and the environmental variables. In this case, the only significant correlation found between the ponderosa pine groups and the stem radial increment phase was the negative correlation with duration of radial increment and mean solar radiation for the PIPO_RD1.2 group. 


\subsection{Discussion}

\subsubsection{Growth Variables}

The significant relationship between magnitude and duration of the same phaseespecially for the expansion and radial increment phases-is a common finding in other studies (Viera et al. 2013; Biondi and Rossi 2015; Deslauriers et al. 2007). The study done by Viera et al. (2013) on maritime pine (Pinus pinaster) in the Mediterranean climate of Portugal attributed the relationship between magnitude and duration of expansion and radial increment in presummer (late June to August) to the long days that occur during this time. Since the days are longer and most expansion (also referred to as recovery) occurs during the night when transpiration slows, the magnitude of expansion is highly dependent and restricted by the duration of time the tree has during the night to expand (Viera et al. 2013). This is similar for radial increment since most radial increment occurs during the night when the tree stem is recovering; for example, if the stem can recover long enough to expand more than it contracted during the day, then a radial increment will occur. Hence, since nights are shorter during the summer, radial increment usually does not occur and rather an overall decrease in stem size often occurs throughout the summer in Mediterranean climates, as seen in Figure 3.2A in the current study and in Viera et al. (2013). The significant positive correlation between magnitude of contraction and magnitude of expansion can most likely be linked to the more negative water potential that is created inside the stem when transpiration rates exceed the rate of water uptake—which also leads to stem shrinkage (contraction) (King et al. 2013). Therefore, as the stem contracts more, the water potential becomes more negative within the stem because it is losing more water to transpiration without being able to replenish it, therefore creating a stronger pull at the roots (Pallardy 2008). This stronger pull created at the roots would then likely pull up more water throughout the night when the stem is recovering during the expansion phase (compared to if the stem shrank less and therefore had a less negative water potential). This is likely why the magnitude of expansion is strongly positively correlated to the magnitude of 
contraction. Liu et al. (2017) also had a similar finding in which they found a positive relationship between amplitude of recovery and magnitude of contraction and highlighted the interdependency of these two phases - this relationship occurred even under drought conditions in the Liupan Mountains of Northwest China.

\subsubsection{Daily Approach}

Similar findings regarding the significant correlations between daily amplitude and solar radiation and relative humidity were also found in Biondi and Rossi (2015) in Pinus monophylla in the Great Basin Desert of North America. However, they compared those variables to the daily stem variations computed from daily averages and daily maxima and did not explicitly state the sign of the correlation. There were some findings that were unique to each species group, however. Regarding the sugar pine groups, PILA_R30C0 and PILA_R30C2 both had a positive correlation between daily amplitude and mean solar radiation, while there were no significant correlations found between these variables for the ponderosa pine group. It is unclear why only sugar pine would have that correlation and not ponderosa pine as well. A study done by King et al. (2013) on larch and spruce trees in the central Swiss Alps also observed increased daily amplitude on days with greater amounts of sunshine. They attributed these observations to the greater evaporative demand on days with stronger solar radiation (King et al. 2013). It is important to note that amplitude is an absolute value calculation for the daily approach-a possible disadvantage regarding the use of the daily approach. Therefore, any value for daily amplitude can mean an overall increase in stem size or an overall decrease in stem size for that day. In this case, it is most likely that the stem size decreased more on those sunnier days.

A finding that was unique to the ponderosa pine group was the negative correlation between daily amplitude and mean air temperature for the PIPO_RD1.2 treatment group. However, King et al. (2013) observed an increase in daily stem amplitude on days with higher temperatures. They attributed this to the increased canopy transpiration and water demands 
that are required on hotter days. This finding does not align with my study in which I observed a negative correlation with daily amplitude and mean air temperature for the RD1.2_PIPO group. However, this difference in findings is likely due to differences in species and climate patterns between the two study areas. The area where King et al. (2013) conducted their study is also relatively dry, but precipitation is distributed evenly throughout the year. This is fairly different to the Mediterranean climate of the Lassen National Forest in which it is warm and dry in the summers with most precipitation occurring during the winter. In this case, it is more likely that the ponderosa pine in the Sierra Nevada closed their stomata on those hotter days to avoid xylem cavitation since they are isohydric species that close their stomata quickly during periods of high water stress (McDowell et al. 2008), whereas there may be enough moisture in the summer in that region of the Swiss Alps to allow trees to keep their stomata open and therefore transpire and contract more. Going back to the positive correlation between daily amplitude and mean solar radiation for the PILA_R30C0 and PILA_R30C2 treatment groups that was not found with the ponderosa pine groups, this could be related to how isohydric or anisohydric sugar pines are. Though information is lacking regarding how isohydric (or anisohydric) sugar pines are, this finding may allude that sugar pines are more likely to keep their stomata open on sunnier (possibly drier) days than ponderosa pines and therefore be more anisohydric than ponderosa pine (therefore closing their stomata less readily during periods with high water stress (McDowell et al. 2008)). If that is the case, sugar pine may be keeping its stomata open on those sunnier days, causing the stem to contract more and have a larger amplitude (though we can only assume the direction of growth when given just the daily amplitudes). A future study done to determine if sugar pines are isohydric or anisohydric may help to explain more of the differences in responses to climate between these species. 


\subsubsection{Stem Cycle Approach}

The magnitude and duration of contraction being negatively correlated with air temperature and solar radiation makes sense when considering the climate of the Sierra Nevada. Since the climate is already warm and dry in the summers (Bigelow et al. 2014; Yeh and Wensel 2000), it is more likely that stomata of the sugar pine and ponderosa pines closed on these hotter days since there is limited water. Viera et al. (2013) had a similar finding in which magnitude of contraction was negatively correlated with maximum temperatures during the summer in the Mediterranean region of Portugal. They attributed this to the high temperatures and low soil water content during the summer causing the trees to control transpiration more-thus causing the stem to contract less on hotter days when the stem is controlling transpiration even more. The duration of contraction and magnitude of contraction being positively correlated to mean relative humidity $(\mathrm{RH})$ does not seem to be a growth response covered in other dendrometer studies. This finding is opposite to what is expected when considering the effect of relative humidity on transpiration rates. Since the water vapor concentration gradient between the leaf and the atmosphere on high $\mathrm{RH}$ days is lower, the tree would not transpire as much compared to a low RH day (Pallardy 2008) when just considering the concentration gradient that is pulling water from the leaf into the atmosphere to drive transpiration. If that is the case, the stem should actually contract less on these days because it would be losing less water relative to a lower $\mathrm{RH}$ day. However, this increase in magnitude and duration of contraction on higher $\mathrm{RH}$ days could also be occurring because the tree is more likely to keep its stomata open to transpire because it does not have as high of a risk of water loss due to the shallower concentration gradient causing a slower transpiration rate (Pallardy 2008). One of the most surprising findings regarding the contraction phase was that the PIPO_Con treatment group had a positive correlation with magnitude of contraction and mean air temperature and solar radiation whereas the PIPO_RD1.2 treatment group had a negative relationship with those environmental variables. This means that the control treatment group 
contracted more on those hotter and sunnier days than the RD1.2 treatment group; the RD1.2 treatment group actually contracted less on those days. This difference between the control and RD1.2 treatment groups for the ponderosa pine species is an early indication that the extended radial release treatments are beneficial. This will be explored more once the stem radial increment correlations are discussed.

The duration of expansion for PIPO_Con was positively correlated to mean solar radiation and mean air temperature but negatively correlated to mean $\mathrm{RH}$. Liu et al. (2017) had a fairly similar finding regarding air temperatures in which they found a positive correlation between stem expansion and maximum air temperature during the dry summer stage defined for their study. Though this finding is similar, it was for maximum air temperature and magnitude of expansion instead of mean air temperature and duration of expansion. However, they are more comparable since duration and magnitude of expansion were positively correlated for the PIPO_Con group (Figure 3.3). They attributed this positive correlation to the fact that air temperature was controlling the stem contraction during the daytime. Therefore, when the stem contracted more during the daytime with increased temperatures, the stem also expanded more during the evening and overnight to try to replenish the lost water from the stem contraction phase (Liu et al. 2017).

The lack of significant correlations between the stem radial increment phase and the environmental variables is likely due to the fact that stem radial increment is not very common during the dry summers in Mediterranean climates; this lack of significant correlations with the increment phase also occurred in Viera et al. (2013). The significant negative correlation of duration and magnitude of radial increment to mean solar radiation and mean air temperature, though not found in either the Viera et al. (2013) or the Liu et al. (2017) studies, can likely be explained by the increasingly dry conditions created on those days from the high temperatures drying out the soil (Viera et al. 2013). Even though contraction is limited on those days as 
explained by Viera et al. (2013), the decreased soil moisture created by the high temperatures in a climate already known for its dry summers would create a microclimate that is not conducive to a stem radial increment being put on.

It is important to note that the magnitude of radial increment of the PILA_RD1.2 treatment group was positively correlated to mean solar radiation. This means that the PILA_RD1.2 group actually put on more radial increment on sunnier days. This finding, along with the previous finding that the PILA_RD1.2 treatment group contracted less on warmer and sunnier days suggests that the PILA_RD1.2 treatment group was less negatively affected by increasing temperatures and solar radiation and that it may even benefit from warmer and sunnier days. This may shed light on the extended radial release RD1.2 treatment being the most effective at releasing these legacy sugar pine trees to improve growth and vigor since trees in this treatment category seemed to be less negatively affected by increasing temperatures and higher solar radiation. A thinning study done by Magruder et al. (2013) found that a moderate thinning intensity $\left(21 \mathrm{~m}^{2} / \mathrm{ha}\right)$ may be best for increasing productivity and climatic resiliency of the remaining trees for a red pine plantation in Michigan. Since my study did not categorize specific thinning intensities and rather categorized radial release sizes, it is hard to make an accurate comparison between the two. However, the diameter based radial release using the RD1.2 treatment may help to apply extended radial release treatments that increase available resources for remaining trees compared to unthinned stands or the standard thinning radius of $9.1 \mathrm{~m}$ used by the USDA Forest Service (Hood et al. 2018). Furthermore, Hood et al. (2018) found that a radial thinning radius of $9.1 \mathrm{~m}$ around legacy ponderosa and Jeffrey pines in the Lassen National Forest, California was not sufficient enough to cause an increase in growth (Basal area increment (BAI)), but it did help to lessen growth decline. Lessening growth decline and a heterogenous canopy structure may then bring about other benefits such as increased drought tolerance and a reduction in wildfire severity and bark beetle attack risk (Hood et al. 
2018). In addition, Hood et al. (2018) suggests a thinning radius larger than $9.1 \mathrm{~m}$ may be sufficient to increase BAI. Therefore, the larger thinning radius that would be applied using the extended thinning radius RD1.2 treatment may be sufficient to increase growth and vigor of the remaining legacy trees_especially for sugar pines. The results from my study indicating that the PILA_RD1.2 contracted less on warmer, sunnier days and put on more radial increment on sunnier days appears to support that claim.

\subsection{Conclusions}

The findings from this chapter highlight the important role that mean solar radiation, air temperature, and relative humidity play in stem variations of sugar and ponderosa pines from the Sierra Nevada region. One of the more significant findings from a management perspective arises is when considering how both positive and negative correlations were found between magnitude of contraction and mean solar radiation and air temperature. The positive correlation with those variables was found for the control treatment group; this means that the control group tended to contract more on those warmer days. The negative correlation with contraction and mean solar radiation and air temperature was found for the RD1.2 treatment group. This means that the trees in this treatment tended to contract less on those warmer days. This suggests that the extended radial thinning treatments likely provided more resources for the residual trees. When looking at the magnitude of stem radial increment, however, the only significant positive correlation with mean solar radiation or air temperatures was found with the PILA_RD1.2 treatment group and mean solar radiation. This makes the negative correlation in the contraction phase seem to be more likely due to increased moisture levels in RD1.2 treatments causing the trees to more readily replenish their stems and therefore contract less. Since they contract less on those hotter and sunnier days, that is possibly why they were more likely to put on stem radial increment on those days. 
It is important to note, however, that this study used environmental variables that were gathered from a nearby weather station in Chester, California. Therefore, these relationships with air temperature, solar radiation, etc. are assuming that these environmental variables are the same within all of the treatment plots. The study was also only done for one summer, so a multiple year study may have different significant findings since it would have more data points. Nonetheless, the main findings from this study highlight that solar radiation, air temperature, and relative humidity play an important role in daily stem fluctuations - and that an extended radial treatment distance (RD1.2) may be the most effective treatment to release and improve growth and vigor of legacy sugar and ponderosa pine trees in the Sierra Nevada region. 
3.6 Appendix 
Table 3.1 Summary table of trees that were measured with dendrometers. PIPO = Pinus ponderosa (ponderosa pine) and PILA = Pinus lambertiana (sugar pine). The control treatment category did not have any radial thinning done; $\mathrm{R} 30 \mathrm{C} 0$ had a constant radial thinning radius of $9.1 \mathrm{~m}$ regardless of $\mathrm{DBH}$; $\mathrm{R} 30 \mathrm{C} 2$ had the same treatment as R30C0 but two competitor trees were left within the $9.1 \mathrm{~m}$ radius; lastly, the RD1.2 treatment radius was determined by multiplying the $\mathrm{DBH}$ in inches by 12 by 1.25 to get a radius (in feet) that was dependent on the $\mathrm{DBH}$.

\begin{tabular}{lllcc}
\hline $\begin{array}{l}\text { Focal } \\
\text { Species }\end{array}$ & $\begin{array}{l}\text { Treatment } \\
\text { Category }\end{array}$ & Plot ID & $\begin{array}{c}\text { Plot Radius } \\
(\mathrm{m})\end{array}$ & $\begin{array}{c}\text { Focal Tree DBH } \\
(\mathrm{cm})\end{array}$ \\
\hline PILA & Control & Con230 & 9.1 & 64.0 \\
PILA & Control & Con234 & 9.1 & 63.8 \\
PILA & Control & Con240 & 16.9 & 117.6 \\
PILA & R30C0 & 122 R30 & 9.1 & 96.0 \\
PILA & R30C0 & $126 R 30$ & 9.1 & 92.2 \\
PILA & R30C0 & $138 R 30$ & 9.1 & 75.9 \\
PILA & R30C2 & $135 R 30 C 2$ & 9.1 & 106.2 \\
PILA & R30C2 & 141 R30C2 & 9.1 & 91.9 \\
PILA & RD1.2 & C2RD1.2 & 18.0 & 120.7 \\
PILA & RD1.2 & C4RD1.2 & 17.4 & 115.6 \\
PILA & RD1.2 & C8RD1.2 & 14.0 & 97.5 \\
\hline PIPO & Control & Con226 & 10.7 & 73.4 \\
PIPO & Control & Con259 & 13.4 & 105.4 \\
PIPO & RD1.2 & C6RD1.2 & 11.3 & 78.0 \\
PIPO & RD1.2 & C7RD1.2 & 13.4 & 86.9 \\
PIPO & RD1.2 & C11RD1.2 & 14.0 & 98.0 \\
\hline
\end{tabular}

Table 3.2 General descriptive statistics of the combined species-treatment groups. The mean plot radius for the control treatments is just for the measurement plots since there were no radial thinning treatments applied to them. The other mean plot radii were the actual mean radii of the radial thinning treatments applied.

\begin{tabular}{ccc}
\hline $\begin{array}{c}\text { Species and } \\
\text { Treatment Group }\end{array}$ & $\begin{array}{c}\text { Mean Plot } \\
\text { Radius }(\mathrm{m})\end{array}$ & $\begin{array}{c}\text { Mean Focal Tree } \\
\text { DBH }(\mathrm{cm})\end{array}$ \\
\hline PILA_Con & 11.7 & 81.8 \\
PILA_R30C0 & 9.1 & 88.1 \\
PILA_R30C2 & 9.1 & 99.1 \\
PILA_RD1.2 & 17.7 & 111.3 \\
PIPO_Con & 12.0 & 89.4 \\
PIPO_RD1.2 & 12.9 & 87.6 \\
\hline
\end{tabular}


Table 3.3 Significant correlations between growth variables. The underscore and number indicate a given phase ( 1 = contraction, 2 = expansion, 3 = radial increment). Magnitude is the absolute value of the difference between the highest and lowest normalized stem growth for a given phase, whereas duration is how long that phase lasted. Values considered significant if after 1000 bootstrapped correlations the 95\% confidence interval did not include zero. Light grey indicates a significant positive correlation between the variables whereas the black color indicates a significant negative correlation (mean correlation noted in cells with significant correlations). Hyphens (-) are noted in cells where comparisons were not made or to avoid duplicate correlations.

\begin{tabular}{|c|c|c|c|c|c|c|}
\hline $\begin{array}{l}\text { Treatment } \\
\text { Group }\end{array}$ & Variable & duration_1 & magnitude_1 & duration_2 & magnitude_2 & duration_3 \\
\hline \multirow{5}{*}{ PILA_Con } & \multirow{5}{*}{$\begin{array}{l}\text { magnitude_1 } \\
\text { duration_2 } \\
\text { magnitude_2 } \\
\text { duration_3 } \\
\text { magnitude_3 }\end{array}$} & & - & - & - & - \\
\hline & & & & - & - & - \\
\hline & & & & 0.61 & - & - \\
\hline & & & & & & - \\
\hline & & & & & & \\
\hline \multirow{5}{*}{ PILA_R30C0 } & \multirow{5}{*}{$\begin{array}{l}\text { magnitude_1 } \\
\text { duration_2 } \\
\text { magnitude_2 } \\
\text { duration_3 } \\
\text { magnitude_3 }\end{array}$} & & - & - & - & - \\
\hline & & -0.32 & & - & - & - \\
\hline & & & & 0.41 & - & - \\
\hline & & & & & & - \\
\hline & & & & & & 0.83 \\
\hline \multirow{5}{*}{ PILA_R30C2 } & \multirow{5}{*}{$\begin{array}{l}\text { magnitude_1 } \\
\text { duration_2 } \\
\text { magnitude_2 } \\
\text { duration_3 } \\
\text { magnitude_3 }\end{array}$} & & - & - & - & - \\
\hline & & & & - & - & - \\
\hline & & & & & - & - \\
\hline & & & -0.64 & & & - \\
\hline & & & & & & \\
\hline \multirow{5}{*}{ PILA_RD1.2 } & \multirow{5}{*}{$\begin{array}{l}\text { magnitude_1 } \\
\text { duration_2 } \\
\text { magnitude_2 } \\
\text { duration_3 } \\
\text { magnitude_3 }\end{array}$} & 0.33 & - & - & - & - \\
\hline & & & & - & - & - \\
\hline & & & 0.85 & & - & - \\
\hline & & & & & & - \\
\hline & & & & & & 0.85 \\
\hline \multirow{5}{*}{ PIPO_Con } & \multirow{5}{*}{$\begin{array}{l}\text { magnitude_1 } \\
\text { duration_2 } \\
\text { magnitude_2 } \\
\text { duration_3 } \\
\text { magnitude_3 }\end{array}$} & & - & - & - & - \\
\hline & & & & - & - & - \\
\hline & & -0.30 & 0.76 & 0.30 & - & - \\
\hline & & & & & & - \\
\hline & & & & & & \\
\hline \multirow{5}{*}{ PIPO_RD1.2 } & \multirow{5}{*}{$\begin{array}{l}\text { magnitude_1 } \\
\text { duration_2 } \\
\text { magnitude_2 } \\
\text { duration_3 } \\
\text { magnitude_3 }\end{array}$} & & - & - & - & - \\
\hline & & & & - & - & - \\
\hline & & & 0.29 & & - & - \\
\hline & & & & & & - \\
\hline & & & & & & \\
\hline
\end{tabular}


Table 3.4 Daily approach analysis. Significant correlation values after running 1000 bootstrapped correlations for each variable. Light grey indicates a significant positive correlation with daily amplitude and a given climate variable for that species-treatment group. Black color indicates a significant negative correlation. If there is a significant correlation, the mean correlation value is indicated within the cell.

\begin{tabular}{|c|c|c|c|c|c|}
\hline $\begin{array}{c}\text { Species and } \\
\text { Treatment } \\
\text { Group }\end{array}$ & Variable & $\begin{array}{c}\text { Mean Solar } \\
\text { Radiation }\end{array}$ & $\begin{array}{c}\text { Mean Air } \\
\text { Temperature }\end{array}$ & Mean RH & $\begin{array}{c}\text { Sum } \\
\text { Precipitation }\end{array}$ \\
\hline PILA_Con & \multirow{6}{*}{$\begin{array}{c}\text { Daily } \\
\text { Amplitude }\end{array}$} & & & & \\
\hline PILA_R30C0 & & 0.23 & & & \\
\hline PILA_R30C2 & & 0.44 & & & \\
\hline PILA_RD1.2 & & & & 0.24 & \\
\hline \multirow{2}{*}{$\begin{array}{l}\text { PIPO_Con } \\
\text { PIPO_RD1.2 }\end{array}$} & & & & 0.32 & \\
\hline & & & -0.37 & 0.25 & \\
\hline
\end{tabular}


Table 3.5 Stem cycle approach analysis. Significant correlation values after running 1000 bootstrapped correlations for each variable. Light grey indicates a significant positive correlation between the variables for that species-treatment group. Black color indicates a significant negative correlation. Mean correlation noted in cells with significant correlations.

\begin{tabular}{|c|c|c|c|c|c|}
\hline $\begin{array}{l}\text { Species and } \\
\text { Treatment } \\
\text { Group }\end{array}$ & Variable & $\begin{array}{c}\text { Mean Solar } \\
\text { Radiation }\end{array}$ & $\begin{array}{c}\text { Mean Air } \\
\text { Temperature }\end{array}$ & Mean RH & $\begin{array}{c}\text { Sum } \\
\text { Precipitation }\end{array}$ \\
\hline PILA_Con & \multirow{6}{*}{$\begin{array}{l}\text { Duration of } \\
\text { Contraction }\end{array}$} & & & & \\
\hline PILA_R30C0 & & & -0.55 & 0.60 & \\
\hline PILA_R30C2 & & -0.91 & & & \\
\hline PILA_RD1.2 & & -0.40 & -0.35 & 0.34 & \\
\hline PIPO_Con & & -0.45 & -0.43 & 0.40 & \\
\hline PIPO_RD1.2 & & -0.64 & -0.42 & 0.53 & \\
\hline \multicolumn{6}{|l|}{ PILA_Con } \\
\hline PILA_R30C0 & \multirow{5}{*}{$\begin{array}{l}\text { Duration of } \\
\text { Expansion }\end{array}$} & -0.20 & & & \\
\hline PILA_R30C2 & & 0.80 & & & \\
\hline PILA_RD1.2 & & & 0.28 & -0.28 & \\
\hline PIPO_Con & & 0.39 & 0.53 & -0.39 & \\
\hline \multicolumn{5}{|l|}{ PIPO_RD1.2 } & \\
\hline \multicolumn{6}{|l|}{ PILA_Con } \\
\hline PILA_R30C0 & \multirow{5}{*}{$\begin{array}{l}\text { Duration of } \\
\text { Radial } \\
\text { Increment }\end{array}$} & & & & \\
\hline PILA_R30C2 & & -0.71 & -0.72 & 0.83 & \\
\hline PILA_RD1.2 & & & & & \\
\hline PIPO_Con & & & & & \\
\hline PIPO_RD1.2 & & -0.38 & & & \\
\hline \multicolumn{6}{|l|}{ PILA_Con } \\
\hline PILA_R30C0 & \multirow{5}{*}{$\begin{array}{l}\text { Magnitude } \\
\text { of } \\
\text { Contraction }\end{array}$} & 0.41 & & & \\
\hline PILA_R30C2 & & & & & \\
\hline PILA_RD1.2 & & -0.49 & -0.40 & 0.45 & \\
\hline PIPO_Con & & 0.29 & 0.27 & & \\
\hline PIPO_RD1.2 & & -0.33 & -0.44 & 0.40 & \\
\hline \multicolumn{6}{|l|}{ PILA_Con } \\
\hline PILA_R30C0 & \multirow{5}{*}{$\begin{array}{l}\text { Magnitude } \\
\text { of } \\
\text { Expansion }\end{array}$} & & & & \\
\hline PILA_R30C2 & & 0.41 & & & \\
\hline PILA_RD1.2 & & 0.71 & 0.42 & & \\
\hline PIPO_Con & & & & & \\
\hline \multicolumn{5}{|l|}{ PIPO_RD1.2 } & \\
\hline \multicolumn{6}{|l|}{ PILA_Con } \\
\hline PILA_R30C0 & \multirow{5}{*}{$\begin{array}{l}\text { Magnitude } \\
\text { of Radial } \\
\text { Increment }\end{array}$} & & & & \\
\hline PILA_R30C2 & & -0.65 & -0.68 & 0.76 & \\
\hline PILA_RD1.2 & & 0.35 & & & \\
\hline PIPO_Con & & & & & \\
\hline PIPO_RD1.2 & & & & & \\
\hline
\end{tabular}




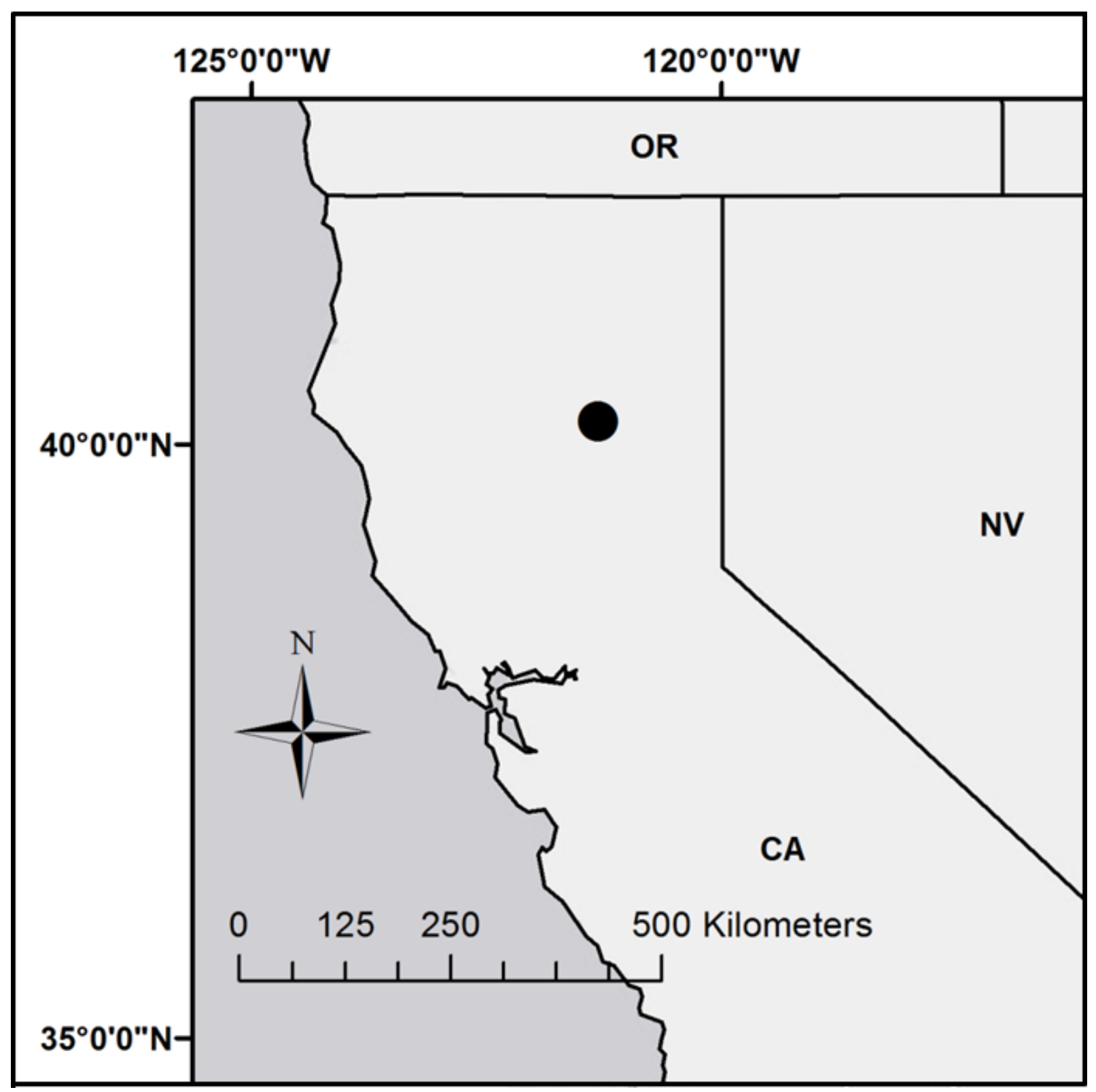

Figure 3.1 Map of study area-located in the southern portion of Lassen National Forest in northern California, just southwest of Lake Almanor. Map courtesy of Johnson et al. (2017). 
A. $126 \mathrm{R} 30$ stem cyclic phases

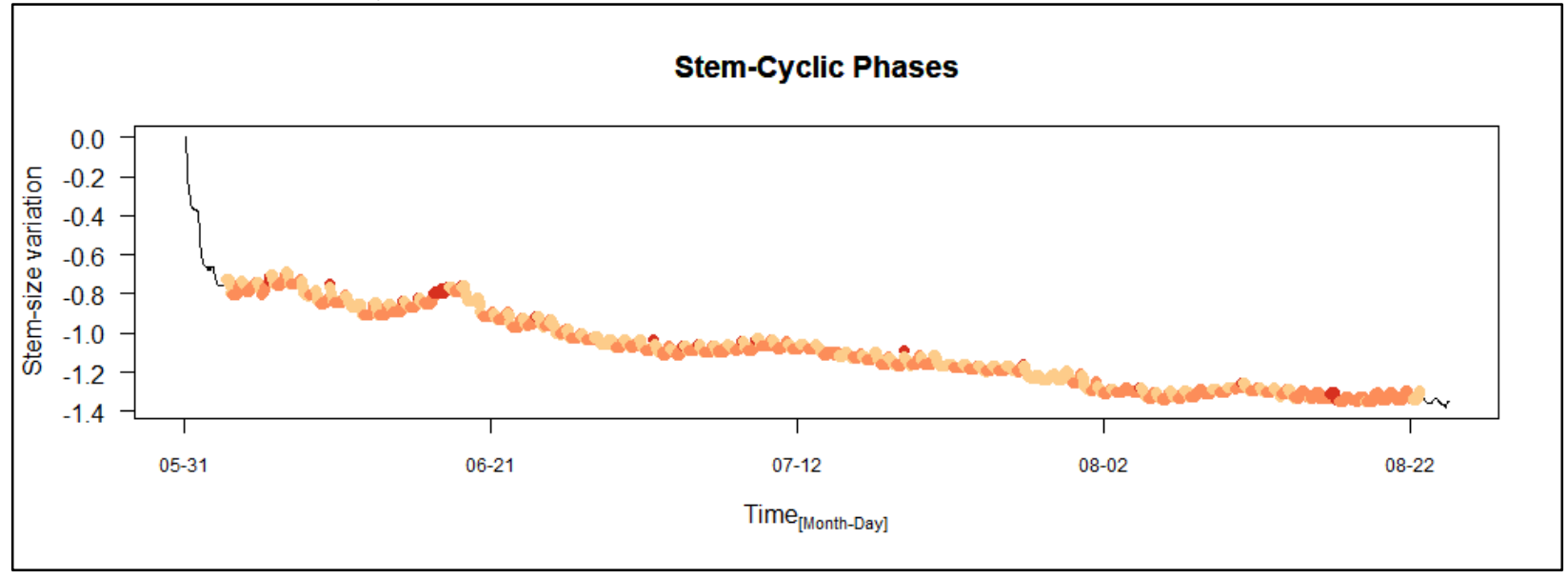

B. PILA_R30C0 stem cyclic phases

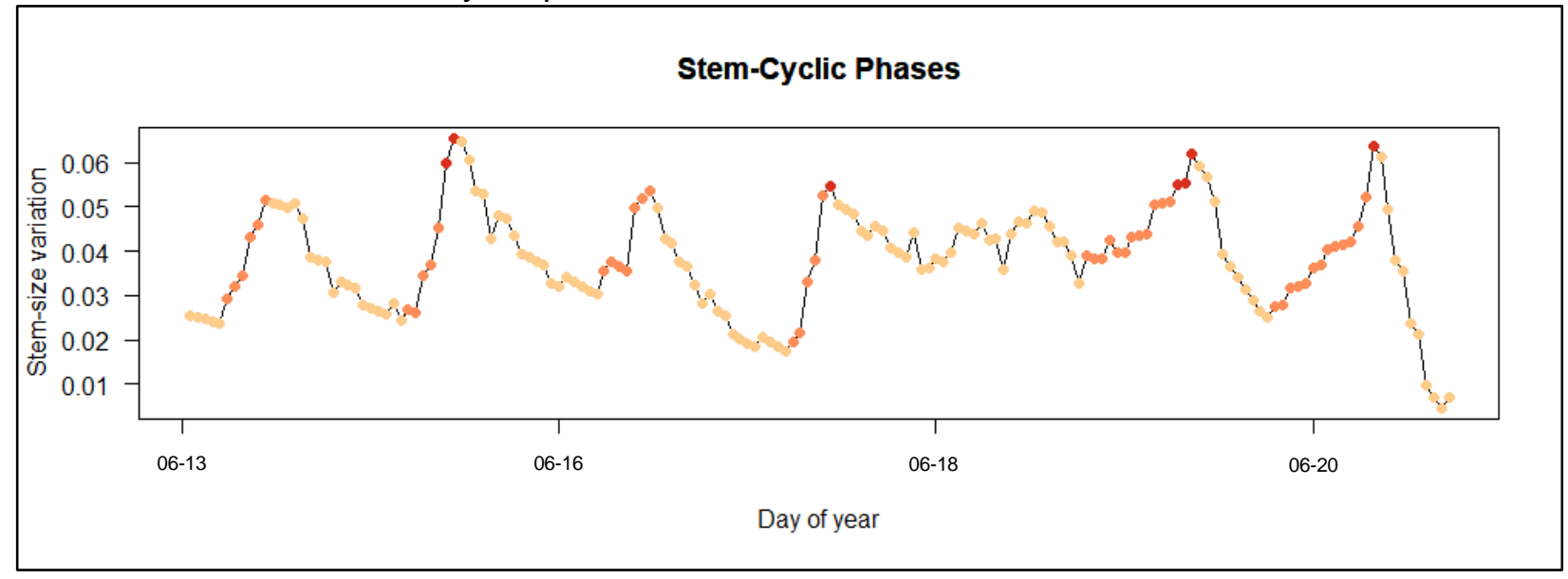

Figure 3.2 Example output of the actual dendrometer data stem cyclic phases for an individual sugar pine tree, 126R30 (A), and for a portion of the normalized dendrometer data showing stem cyclic phases of the PILA_R30C0 treatment group (B). Yellow indicates contraction (phase 1), orange indicates expansion (phase 2), and red indicates stem radial increment (phase 3). Stem radial increment occurs when the stem expands further than the previous maximum. 
A. Solar radiation

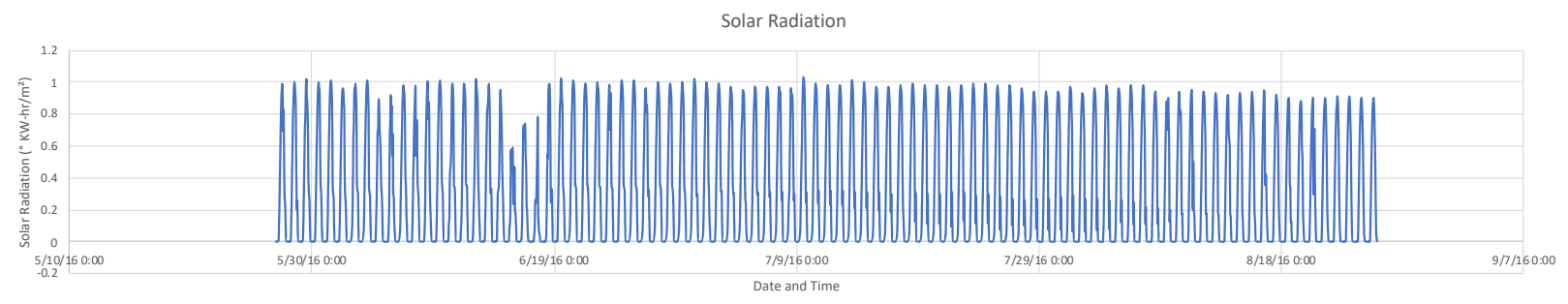

B. Mean air temperature

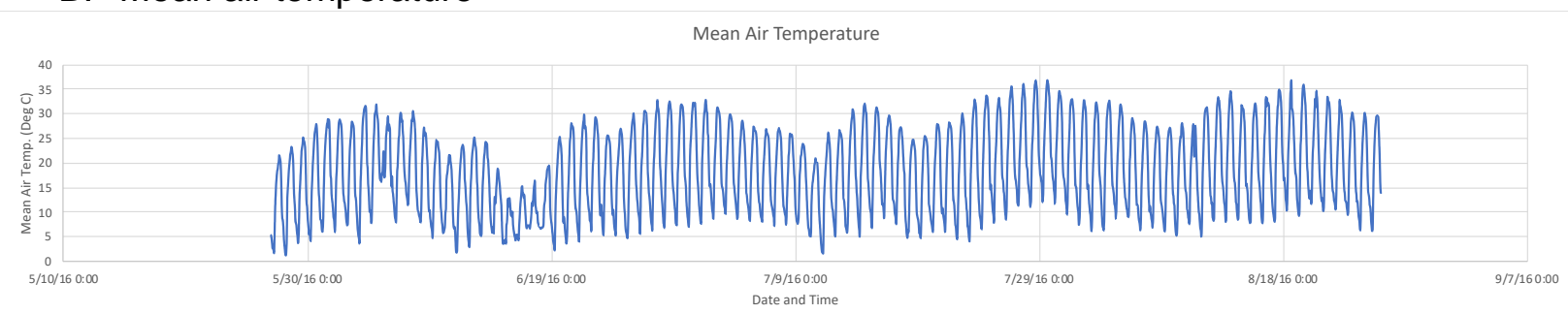

C. Mean relative humidity

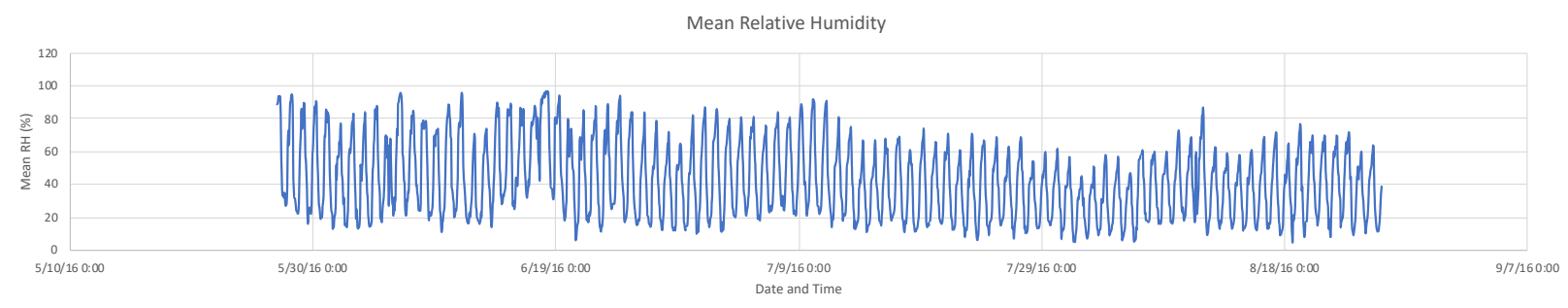

D. Total precipitation

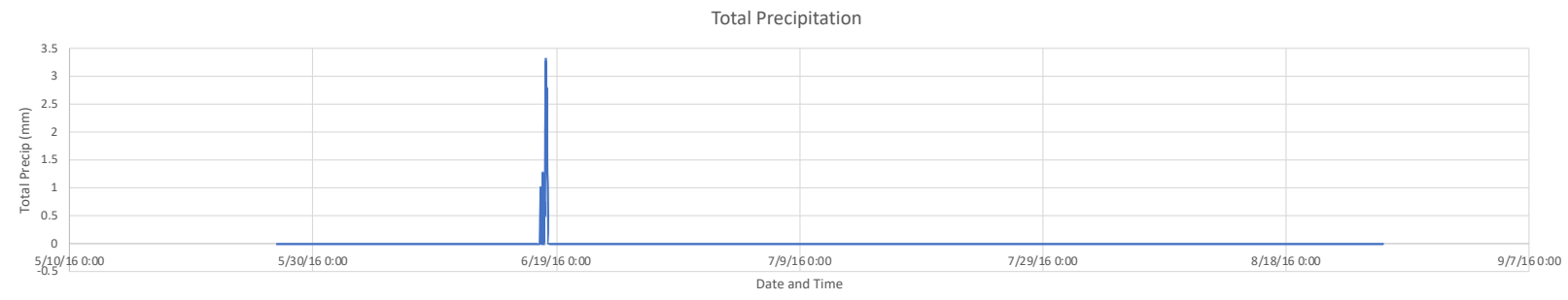

Figure 3.3 Chester RAWs weather station for the measurement period. Data shown here is from the time of the first dendrometer measurement to the last dendrometer measurement. 
3.7 References 
Bailey, R.G., 1994. Ecoregions of the United States. USDA Forest Service. Available online: https://www.fs.usda.gov/rmrs/ecoregions-united-states

Bentz, B.J., Regniere, J., Fettig, C.J., Hansen, E.M., Hayes, J.L., Nicke, J.A., Kelsey, R.G., Negron, J.F., and Seybold, S.J. 2010. Climate change and bark beetles of the western United States and Canada: direct and indirect effects. BioScience 60:602-613.

Bigelow, S.W., Papaik, M.J., Caum, C., North, M.P., 2014. Faster growth in warmer winters for large trees in a Mediterranean-climate ecosystem. Clim. Change 123, 215-224. https://doi.org/10.1007/s10584-014-1060-0

Biondi, F., Rossi, S., 2015. Plant-water relationships in the Great Basin Desert of North America derived from Pinus monophylla hourly dendrometer records. Int. J. Biometeorol. 59, 939953. https://doi.org/10.1007/s00484-014-0907-4

Bradford, J.B., Bell, D.M., 2017. A window of opportunity for climate-change adaptation: easing tree mortality by reducing forest basal area. Front. Ecol. Environ. 15, 11-17. https://doi.org/10.1002/fee.1445

Chhin, S., Hogg, E.H., Lieffers, V.J., Huang, S., 2010. Growth-climate relationships vary with height along the stem in lodgepole pine. Tree Physiol. 30, 335-345. https://doi.org/10.1093/treephys/tpp120

Deslauriers, A., Anfodillo, T., Rossi, S., Carraro, V., 2007. Using simple causal modeling to understand how water and temperature affect daily stem radial variation in trees. Tree Physiol. 27, 1125-1136. https://doi.org/10.1093/treephys/27.8.1125

Deslauriers, A., Morin, H., Urbinati, C., Carrer, M., 2003. Daily weather response of balsam fir (Abies balsamea (L.) Mill.) stem radius increment from dendrometer analysis in the boreal forests of Québec (Canada). Trees - Struct. Funct. 17, 477-484. https://doi.org/10.1007/s00468-003-0260-4

Duchesne, L., Houle, D., 2011. Modelling day-to-day stem diameter variation and annual growth of balsam fir (Abies balsamea (L.) Mill.) from daily climate. For. Ecol. Manage. 262, 863872. https://doi.org/10.1016/j.foreco.2011.05.027

Fecko, R.M., Walker, R.F., Frederick, W.B., Miller, W.W., Johnson, D.W., 2008. Stem dimensional fluctuation in Jeffrey pine from variation in water storage as influenced by thinning and prescribed fire. Ann. For. Sci. 65. https://doi.org/10.1051/forest:2007084

Fettig, C.J., Klepzig, K.D., Billings, R.F., Munson, A.S., Nebeker, T.E., Negron, J.F., and Nowak, J.T. 2007. The effectiveness of vegetation management practices for prevention and control of bark beetle outbreaks in coniferous forests of the western and southern United States. For. Ecol. Manag. 238:24-53.

Fulé, P.Z., Crouse, J.E., Roccaforte, J.P., Kalies, E.L., 2012. Do thinning and/or burning treatments in western USA ponderosa or Jeffrey pine-dominated forests help restore natural fire behavior? For. Ecol. Manage. 269, 68-81. https://doi.org/10.1016/j.foreco.2011.12.025 
Hood, S.M., Cluck, D.R., Jones, B.E., Pinnell, S., 2018. Radial and stand-level thinning treatments: 15-year growth response of legacy ponderosa and Jeffrey pine trees. Restor. Ecol. 26, 813-819. https://doi.org/10.1111/rec.12638

IPCC, 2013: Climate Change 2013: The Physical Science Basis. Contribution of Working Group I to the Fifth Assessment Report of the Intergovernmental Panel on Climate Change [Stocker, T.F., D. Qin, G.-K. Plattner, M. Tignor, S.K. Allen, J. Boschung, A.

King, G., Fonti, P., Nievergelt, D., Büntgen, U., Frank, D., 2013. Climatic drivers of hourly to yearly tree radius variations along a $6^{\circ} \mathrm{C}$ natural warming gradient. Agric. For. Meteorol. 168, 36-46. https://doi.org/10.1016/j.agrformet.2012.08.002

Liu, Z., Wang, Yanhui, Tian, A., Yu, P., Xiong, W., Xu, L., Wang, Yarui, 2017. Intra-annual variation of stem radius of Larix principis-rupprechtii and its response to environmental factors in Liupan Mountains of Northwest China. Forests 8, 1-16. https://doi.org/10.3390/f8100382

Luers, A.L., Cayan, D.R., Franco, G., Hanemann, M., Croes, B., 1990. Our changing climate. Agric. For. Meteorol. 50, 55-64. https://doi.org/10.1016/0168-1923(90)90138-V

Magruder, M., Chhin, S., Palik, B., Bradford, J.B., 2013. Thinning increases climatic resilience of red pine. Can. J. For. Res. 43, 878-889. https://doi.org/10.1139/cjfr-2013-0088

McDowell, N., Pockman, W.T., Allen, C.D., Breshears, D.D., Cobb, N., Kolb, T., Plaut, J., Sperry, J., West, A., Williams, D.G., Yepez, E.A., 2008. Mechanisms of plant survival and mortality during drought: Why do some plants survive while others succumb to drought? New Phytol. 178, 719-739. https://doi.org/10.1111/j.1469-8137.2008.02436.x

Pallardy, S.G., 2008. Physiology of Woody Plants, 3rd Edition. Elsevier Inc.

USDA Forest Service, 1999. M261 Sierran Steppe-Mixed Forest-Coniferous Forest-Alpine Meadow Province. Available online:

https://www.fs.fed.us/land/ecosysmgmt/colorimagemap/images/m261.html

van der Maaten, E., Maaten-Theunissen, van der, Smiljanić, M., Rossi, S., Simard, S., Wilmking, M., Deslauriers, A., Fonti, P., von Arx, G., Bouriaud, O., 2016. dendrometeR: Analyzing the pulse of trees in R. Dendrochronologia 40, 12-16.

Vegetronix, 2021. VH400 Piecewise Curve. Available online: https://vegetronix.com/Products/VH400/VH400-Piecewise-Curve.phtml

Vieira, J., Rossi, S., Campelo, F., Freitas, H., Nabais, C., 2013. Seasonal and daily cycles of stem radial variation of Pinus pinaster in a drought-prone environment. Agric. For. Meteorol. 180, 173-181. https://doi.org/10.1016/j.agrformet.2013.06.009

Wang, J., Sammis, T.W., 2008. New automatic band and point dendrometers for measuring stem diameter growth. Appl. Eng. Agric. 24, 731-742. 
Yeh, H.Y., Wensel, L.C., 2000. The relationship between tree diameter growth and climate for coniferous species in northern California. Can. J. For. Res. 30, 1463-1471. https://doi.org/10.1139/x00-074

Ziaco, E., Biondi, F., 2018. Stem circadian phenology of four pine species in naturally contrasting climates from sky-island forests of the western USA. Forests 8.

https://doi.org/10.3390/f9070396 


\section{Chapter 4: General Conclusions}

With impacts of climate change and previous fire suppression threatening the health and vigor of Sierra Nevada mixed conifer forests, it is becoming increasingly important to further our understanding of climatic drivers of growth in these forests as well as the effectiveness of current management techniques attempting to mitigate these issues. It is also important to understand how small-, medium-, and large-sized trees were affected by historic climate to help us fine-tune our management efforts on the tree sizes we are most interested in managing for. Furthermore, given the multiple ecosystem benefits that legacy trees provide in the Sierra Nevada region, the effects of the radial release treatments that are being applied more often around these trees needs to be further researched. In this thesis, I performed a dendroclimatic analysis to determine climatic drivers of growth of small-, medium-, and large-sized mixed conifer species in the northern Sierra Nevada region. I also analyzed hourly dendrometer data collected on sugar and ponderosa pines in multiple different radial release treatments to assess climatic drivers of hourly stem fluctuations. This was done to further our understanding of climatic drivers of growth as well as to try and provide short-term results of these radial release treatments. Findings from the analysis of the dendrometer data will help guide future decisions on which radial release treatments may be best to release legacy sugar and ponderosa pine trees-until longer-term effects can be analyzed.

The findings from my dendroclimatic analysis highlight how Sierra Nevada mixed conifer species of different sizes may be affected differently in a future changing climate. More specifically, larger trees may be more negatively affected by increasing summer and fall temperatures in the future and may also carry over those negative effects into the next year. Though smaller trees were sometimes negatively affected by these increasing temperatures, they rarely carried those negative affects into the next year. However, trees of all sizes may benefit from increasing minimum winter temperatures. Future dendroclimatic studies looking to explore other influences on smaller tree growth patterns may want to look into more 
microclimatic factors affecting growth in the understory. Using such microclimatic factors, along with the factors already analyzed in this study, may help to explain a higher percentage of ring width variation in those smaller trees.

The analysis of the dendrometer data collected on sugar pine and ponderosa pine further highlighted the important role that air temperature plays in the growth of Sierra Nevada mixed conifer species. Furthermore, this analysis found that air temperature, solar radiation and relative humidity all play an important role in hourly stem fluctuations. While some treatment groups such as the PIPO_Con treatment group contracted more on warmer and higher solar radiation days, the RD1.2 treatment group for both sugar and ponderosa pine contracted less on those days. This suggests that the extended radial release RD1.2 treatment may be providing more resources for the residual trees. The only positive correlation found between the magnitude of stem radial increment and mean solar radiation or air temperature was found for PILA_RD1.2 and mean solar radiation. This means that the PILA_RD1.2 treatment group contracted less on warmer, sunnier days and actually put on growth on sunnier days (the only treatment group to do this). In addition to furthering our understanding of climatic drivers of hourly stem fluctuations, these findings provide early indications as to the outcomes of the radial treatments applied in the study area. More specifically, these findings suggest that the extended radial release treatment may be the most effective at releasing these legacy sugar and ponderosa pine trees in the northern Sierra Nevada region. 